\title{
Determining the Optimal Order Quantity with Compound Erlang Demand under (T,Q) Policy
}

\author{
Aiping Jiang $\mathbb{D},{ }^{1}$ Kwok Leung Tam, ${ }^{2}$ Yingzi Bao, ${ }^{1}$ and Jialing Lu $\mathbb{C}^{1}$ \\ ${ }^{1}$ SHU-UTS SILC Business School, Shanghai University, 20 Chengzhong Road, Jiading District, Shanghai 201899, China \\ ${ }^{2}$ School of Mathematics and Statistics, UNSW, Sydney, NSW 2052, Australia \\ Correspondence should be addressed to Aiping Jiang; ap724@shu.edu.cn
}

Received 10 March 2018; Revised 25 June 2018; Accepted 12 July 2018; Published 19 August 2018

Academic Editor: Neale R. Smith

Copyright (c) 2018 Aiping Jiang et al. This is an open access article distributed under the Creative Commons Attribution License, which permits unrestricted use, distribution, and reproduction in any medium, provided the original work is properly cited.

\begin{abstract}
Management of electric equipment has a direct impact on companies' performance and profitability. Considering the critical role that electric power materials play in supporting maintenance operations and preventing equipment failure, it is essential to maintain an inventory to a reasonable level. However, a majority of these electric power materials exhibit an intermittent demand pattern characterized by random arrivals interspersed with time periods with no demand at all. These characteristics cause additional difficulty for companies in managing these electric power material inventories. In response to the above problem, this paper, based on the electric power material demand data of Shanghai Electric Power Company, develops a new method to determine the optimal order quantity $Q^{*}$ in a cost-oriented periodic review $(T, Q)$ system, whereby unsatisfied demands are backordered and demand follows a compound Erlang distribution. $Q^{*}$ corresponds to the value of $Q$ that gives the minimum expected total inventory holding and backordering cost. Subsequently, an empirical investigation is conducted to compare this method with the Newsvendor model. Results verify its superiority in cost savings. Ultimately, considering the complicated calculation and low efficiency of that algorithm, this paper proposes an approximation and a heuristic algorithm which have a higher level of utility in a real industrial context. The approximation algorithm simplifies the calculation process by reducing iterative times while the heuristic algorithm achieves it by generalizing the relationship between the optimal order quantity $Q^{*}$ and mean demand interarrival rate $\lambda$.
\end{abstract}

\section{Introduction}

When managing electric power material inventories, companies need to decide when to order and how much to order so as to maintain the appropriate inventory level. Considering that a majority of electric power materials exhibit an intermittent demand pattern, effective management of these electric power materials is essential to electric power companies. Intermittent demand appears at random, with time intervals during which no demand occurs. These characteristics make inventory control a rather challenging task. These electric power materials are usually characterized by low usage frequency, long intervals, and irregular demand. Furthermore, demand arrivals and sizes vary with usage and maintenance patterns,-further adding to the degree of intermittence. Moreover, the historical data of electric power materials are limited, coupled with constraints on the forecasting method, demand forecast for these electric power materials is difficult.
However, such electric power materials are usually essential components of expensive electric equipment. In the case of equipment failure, when electric power materials are unavailable and need to be ordered immediately, the cost of these urgent orders is higher than regular orders, significantly increasing the maintenance cost. In addition to this, the failure of a component in the electrical equipment is likely to lead to equipment failure, generating a high backordering cost and economic loss. On the other hand, excessive stock of electric power materials leads to backlogs and erosion, resulting in a significant waste of capital as well as the corresponding corporate cost. Some electric power materials stored in warehouses for a long time erode before they are put into use, while some are permanently idle due to the continuous changes and updates of electrical equipment. Since traditional inventory control is generally designed for regular demand, its application to intermittent demand is likely to lead to frequent stock-out events or excessive stock, 
making the inventory control of electric power materials a more challenging task. Thus, it is essential for electric power companies to control their intermittent electric power material inventories.

\section{Research Background}

In this section, a brief review of the literature related to intermittent material inventory control is undertaken.

Traditional inventory control systems generally focus on regular demand and are not suitable for intermittent demand (Adelson [1]; Friend [2]). As a representative of traditional inventory control models, the Newsvendor model had been extensively used since it was introduced in 1962 (Hanssman [3]). This model states that if inventory is larger than demand, the remaining inventory will be sold at a discounted price or disposed at the end of period; however, if inventory is smaller than demand, some profit will be lost. Thus this model focuses on optimizing cost or profit and develops relevant inventory policy. Subsequently a great number of scholars make extensions to this traditional model which can be divided into three categories. Firstly, traditional models usually assume a fixed purchase price which departs from the reality. Thus price-sensitive demand is introduced. For instance, Xiao et al. [4] study the price-dependent demand in a multi-product Newsvendor model and propose corresponding methods of obtaining the optimal order quantity and optimal sales price. Kébé et al. [5] consider a two-echelon inventory lot-sizing problem with price-dependent demand and develop a mixed-integer programming formulation as well as a Lagrangian relaxation solution procedure for solving this problem. Secondly, considering the profound influence of demand variation on expected profits or costs, plenty of scholars focus on the modelling of demand when studying Newsvendor model. Uduman [6] employs demand distributions satisfying the SCBZ (clock back to zero) property to model the single demand for a single product, namely, newspaper, and subsequently obtain the optimal order quantity. Fathima et al. [7] study the generalization of Uduman's model with several individual demands for a single product, followed by numerical illustrations. Furthermore, Faithma \& Uduman [8] propose an approximation closed-form optimal solution for three cases of single period inventory model, in which the demand varies with the SCBZ property. In addition to SCBZ property, Kamburowski [9] developed a theoretical framework for analyzing the distribution-free Newsboy problems due to incomplete information. Similarly, Chen [10] considers unknown demand and demonstrates the appropriateness of applying the bootstrap method to Newsvendor model. Hnaien et al. [11] focus on discrete distributions of probabilities of demand. Besides, Priyan \& Uthayakumar [12] consider a two-echelon multi-product multi-constraint inventory model with product returns and recovery. Lastly, two-level Newsvendor model including inventories on raw materials and finished products has recently received increasingly attention. In such model, Keramatpour et al. [13] develop a meta-heuristic algorithm to obtain the optimal solution which optimize profit and service level simultaneously.
Axsäter [14] reveals that a majority of inventory control models including Newsvendor model are built on some assumptions, for instance, that lead-time demand follows the normal distribution. However, they point out that although this assumption is reasonable in most cases, it is inconsistent with the reality in certain circumstances and leads to a waste of capital or low service levels. Thus, they propose the $(R$, $Q)$ policy with the compound Poisson demand. Considering that the compound distribution model can determine arrival and demand sizes, respectively, and its structure is similar to the intermittent demand process, a vast number of scholars propose that compound distributions, compound Poisson distribution in particular, can offer a good fit for intermittent material inventory (Adelson [1]; Friend [2]). Similarly, Matheus and Gelder [15] also employ compound Poisson distribution to model demand and determine the order quantity and reorder points. Babai et al. [16] have developed a method to determine the optimal order-up-to level, subject to a compound Poisson distribution.

Dunsmuir and Snyder [17] present a method for determining an optimal reorder point for the continuous review $(S, Q)$ inventory policy, subject to a compound Bernoulli demand. However, they fail to take the impact of lead-time demand on the service level into account. To fill the gap, Janssen et al. [18] make some modifications and adopt the $(R, s, Q)$ inventory model to calculate the reorder point with a service-level restriction. Teunter et al. [19] restrict their study to the calculation of the mean and variance of lead time demand and derive closed-form expressions for the service level and the expected total cost under the $(T, S)$ policy with a compound binomial demand, thereby avoiding complicated calculation of the mean and variance.

Of all the literature with compound demand distribution assumptions, the compound Poisson is the most widely utilized. Its popularity can be mainly attributed to the simplicity arising from the memoryless propensity of the exponential distribution of the demand interarrivals. Gupta et al. [20] introduce the Palm's theorem to justify such demand modelling for whole complicated systems. However, in the case of one single material, this modelling is reported to lead to excess stock and imposes an additional financial burden on companies (Smith and Dekker [21]).The memoryless propensity implies a constant failure rate, which is inconsistent with the reality, where the likelihood of the failure of an item and the demand for it grows with time. Smith and Dekker [21] initially propose a more realistic renewal demand arrival process which has an Increasing Failure Rate (IFR), but they do not propose specific demand distribution to model the renewal demand arrival process. Subsequently Larsen and Kiesmuller [22] provide the first insight into the employment of compound Erlang distribution- $\mathrm{k}$ in the inventory control system and they derive a closed-form cost expression of the optimal reorder level for an $(R, s, n Q)$ policy. Based on the same demand distribution, Larsen and Thorstenson [23] consider a continuous review base stock policy and demonstrate the use of a computer program to obtain the base stock level needed to achieve the specified order fill rate (OFR) and volume fill rate (VFR), respectively. Moreover, the respective performances of the OFR and VFR 
for different inventory control systems are compared (Larsen and Thorstenson [24]). With demand arrivals following the Erlang distribution, in conjunction with a Gamma distribution for demand size, Saidane et al. $[25,26]$ propose an algorithm to determine the optimal base stock level under a costoriented continuous review inventory system and conduct numerical investigations to compare the performance of this model in cost reduction with that of the compound Poisson distribution and the classic Newsvendor model, respectively. Syntetos et al. [27] not only demonstrate the superiority of deviating from the memoryless demand model, but also take the degree of intermittence into consideration and explore its connection with forecast accuracy through a numerical investigation. In sum, the above literature under a compound Erlang process all assume that the lead time is constant.

In spite of the many contributions to the material inventory management field, there are some shortcomings that need to be addressed. Firstly, the majority of research focuses on the service-oriented rather than cost-oriented inventory systems. For instance, Matheus and Gelder [15] demonstrate a simpler method to calculate the optimal reorder point subject to a compound Poisson demand due to the assumption of a target service level. Fung et al. [28] build a model of periodreview with an order-up-to-level $(T, S)$ policy for single-item inventory systems under compound Poisson demands and service-level constraints. Zhao [29] evaluates an Assembleto-Order (ATO) system under compound Poisson demand with a batch ordering policy by means of service level, including the delivery lead-times and the order-based fill rates. Topan and Bayindir [30] explore the multi-item two-echelon material inventory system with compound Poisson demand and constraints on the aggregate mean response time, which is an indicator of a target service level. In addition, the proposed algorithm is not able to be implemented since it is complicated and does not fit bulk operation.

In response to these shortcomings, this paper is based on the electric power material demand data of Shanghai Electric Power Company and develops a method to determine the optimal order quantity with the $(T, Q)$ policy, subject to the compound Erlang demand. Empirical analysis is conducted to verify the superiority of the proposed theoretical model in cost reductions, as compared to the Newsvendor model. This paper also proposes an approximation and a heuristic algorithm to overcome the inconvenience and low efficiency of existing algorithms in the real world.

\section{The Optimal Order Quantity Model with Compound Erlang Demand and (T,Q) Policy}

\subsection{Problem Description and Model Assumptions}

3.1.1. Problem Description. This paper explores the inventory control of electric power materials with intermittent demand, which is a rather challenging task with tremendous cost implications for companies holding these inventories. The relevant cost mainly consists of holding cost incurred for each unit kept in stock and backordering cost arising from excess demand. Intermittent demand is modelled as a more realistic compound Erlang-k distribution which has an IFR. We consider a cost-oriented single echelon single-item inventory system where unfilled demand is backordered and lead time is deterministic. The stock level is controlled according to a periodic review $(T, Q)$ policy, which means that an order with fixed-amount quantity $Q$ is triggered every inspection interval $T$. The stock level is recorded as holding cost if $Q$ exceeds the total demand sizes within the lead time and as backordering cost if not.

3.1.2. Model Assumptions. This section shows relevant notations and assumptions of the inventory control model proposed in this paper.

We introduce the following notations:
$L:$ lead time (constant)
Q: order quantity
$X$ : demand size (random variable)
$\emptyset_{\mathrm{X}}$ : probability distribution function of demand sizes
$\beta$ : mean of nonzero demand sizes
$\lambda$ : mean demand arrival rate
$k$ : the number of Erlang stages
$T$ : inspection interval
$h$ : inventory holding cost per SKU (Stock Keeping Unit) per unit of time
$b$ : inventory backordering cost per SKU per unit of time
$i$ : the complex number

For the proposed model, the following assumptions are made.

(1) A single echelon single-item inventory system, which means that only a particular item in a particular echelon of the supply chain is considered in the inventory system.

(2) A periodic review $(T, Q)$ policy, where periodic inspections are performed every cycle time of $\mathrm{T}$ and a fixed-amount Qorder quantity is subsequently generated. This policy means that organizations do nothing to control inventory within a cycle.

(3) The compound Erlang demand process, where demand arrivals are governed by Erlang distribution and demand sizes are governed by an arbitrary nonnegative probability distribution.

(3) Constant lead time.

(4) The total inventory cost consisting of inventory holding cost and backordering cost. Inventory holding cost is incurred for each unit kept in stock while backordering cost is due to the excess demand.

3.2. Model Analysis. The model proposed in this paper presents demand as a compound Erlang process where demand arrivals are governed by an Erlang-k distribution and demand sizes are governed by an arbitrary nonnegative probability distribution. According to the above assumptions, the total expected inventory cost consists of the holding cost $h$ and backordering cost $b$. Assuming that the probability of nodemand arrivals during the lead time is $P_{0}$, the expected 
cost equals $h Q P_{0}$. When there are $m$ demand arrivals with a total size of $X_{m}$ during the lead time, the inventory holding cost constitutes the total cost when $\mathrm{Q}-X_{m}>0$, while the backordering cost constitutes the total cost when $\mathrm{Q}-X_{m}<0$. Thus, the expected total cost is given as follows:

$$
\begin{aligned}
& \mathrm{E}[C(\mathrm{Q})]=h \mathrm{Q} P_{0} \\
& +\sum_{m=1}^{+\infty}\left[h \int_{0}^{\mathrm{Q}}\left(Q-X_{m}\right) P_{m} d \emptyset_{X_{m}}^{(m)}\left(X_{m}\right)\right. \\
& \left.+b \int_{\mathrm{Q}}^{+\infty}\left(X_{m}-Q\right) P_{m} d \emptyset_{X_{m}}^{(m)}\left(X_{m}\right)\right]
\end{aligned}
$$

Note that the probability distribution of $X_{m}$ demand size $\emptyset_{X_{m}}^{(m)}$ is the m-fold iterated convolution of $\emptyset_{X}$. Besides, the probability of $m$ demand arrivals within the lead time $P_{m}$ in formula (1) can be derived based on the queuing and renewal theories (Saidane et al. [26]):

$$
P_{m}=\sum_{i=0}^{k-1} \frac{(k \lambda L)^{(k m+i)}}{(k m+i) !} e^{-k \lambda L} \quad(m \geq 0)
$$

The objective of this paper is to derive the optimal order quantity $Q^{*}$, minimizing the expected total cost. Since $\mathrm{E}[C(Q)]$ is a convex function, it can be obtained by setting the derivative of the expected total cost with respect to $Q$ equal to zero:

$$
\frac{\mathrm{dE}[C(Q)]}{\mathrm{dQ}}=h P_{0}+\sum_{m=1}^{+\infty}\left[(h+b) \emptyset_{X_{m}}^{(m)}(Q)-b\right] P_{m}=0
$$

Proposition 1. The optimal order quantity $Q^{*}$ is the solution of

$$
\begin{gathered}
\sum_{m=1}^{+\infty} \emptyset_{X_{m}}^{(m)}\left(Q^{*}\right) \sum_{i=0}^{k-1} \frac{(k \lambda L)^{(k m+i)}}{(k m+i) !} e^{-k \lambda L} \\
=\frac{b}{h+b}-\sum_{i=0}^{k-1} \frac{(k \lambda L)^{(i)}}{i !} e^{-k \lambda L}
\end{gathered}
$$

Proof. The optimal order quantity $Q^{*}$ is the solution of the derivative of the expected total cost with respect to $\mathrm{Q}$ which equals zero:

$$
\frac{\mathrm{dE}[C(\mathrm{Q})]}{\mathrm{dQ}}=0
$$

which is equivalent to

$$
\frac{\mathrm{dE}[C(Q)]}{\mathrm{dQ}}=h P_{0}+\sum_{m=1}^{+\infty}\left[(h+b) \emptyset_{X_{m}}^{(m)}(Q)-b\right] P_{m}=0
$$

Thus

$$
\sum_{m=1}^{+\infty} \emptyset_{X_{m}}^{(m)}(Q) P_{m}=\frac{b}{h+b} \sum_{m=1}^{+\infty} P_{m}-\frac{h}{h+b} P_{0}
$$

Considering that $\sum_{m=1}^{+\infty} P_{m}=1-P_{0}$, the optimal order quantity $Q^{*}$ can be derived from

$$
\begin{gathered}
\sum_{m=1}^{+\infty} \emptyset_{X_{m}}^{(m)}\left(Q^{*}\right) \sum_{i=0}^{k-1} \frac{(k \lambda L)^{(k m+i)}}{(k m+i) !} e^{-k \lambda L} \\
=\frac{b}{h+b}-\sum_{i=0}^{k-1} \frac{(k \lambda L)^{(i)}}{i !} e^{-k \lambda L}
\end{gathered}
$$

Since formula (8) is the infinite sum, this paper uses an upper bound $Q_{U}$ and a lower bound $Q_{L}$ to approximate the optimal order quantity $Q^{*}$. In order to derive $Q_{U}$ and $Q_{L}$, we denote that

$$
\begin{aligned}
G\left(X_{m}, n\right)= & \sum_{m=1}^{n} \emptyset_{X_{m}}^{(m)}(Q) P_{m}-\frac{b}{h+b}+P_{0} \\
& +\left(1-\sum_{m=0}^{n} P_{m}\right) \\
H\left(X_{m}, n\right)= & \sum_{m=1}^{n} \emptyset_{X_{m}}^{(m)}(Q) P_{m}-\frac{b}{h+b}+P_{0} \\
O\left(X_{m}\right)= & \sum_{m=1}^{+\infty} \emptyset_{X_{m}^{(m)}}(Q) P_{m}-\frac{b}{h+b}+P_{0}
\end{aligned}
$$

Property 2. $H\left(X_{m}, n\right) \leq O\left(X_{m}\right) \leq G\left(X_{m}, n\right)$, for all $X_{m}, n \geq$ 0.

Proof.

$$
\begin{aligned}
O\left(X_{m}\right)= & \sum_{m=1}^{+\infty} \emptyset_{X_{m}}^{(m)}(Q) P_{m}-\frac{b}{h+b}+P_{0} \\
= & \sum_{m=1}^{n} \emptyset_{X_{m}}^{(m)}(Q) P_{m}-\frac{b}{h+b}+P_{0} \\
& +\sum_{m=n}^{n+\infty} \emptyset_{X_{m}}^{(m)}(Q) P_{m} \\
= & H\left(X_{m}, n\right)+\sum_{m=n}^{+\infty} \emptyset_{X_{m}}^{(m)}(Q) P_{m}
\end{aligned}
$$

Since $0 \leq \emptyset_{X_{m}}^{(m)}(Q) \leq 1$ for any $X_{m}, m \geq 0$,

$$
0 \leq \sum_{m=n}^{+\infty} \emptyset_{X_{m}}^{(m)}(Q) P_{m} \leq \sum_{m=n}^{+\infty} P_{m}, \quad \text { for all } X_{m}, n \geq 0
$$

Thus $H\left(X_{m}, n\right) \leq O\left(X_{m}, n\right)$ :

$$
\begin{aligned}
O\left(X_{m}\right) & =\sum_{m=1}^{+\infty} \emptyset_{X_{m}}^{(m)}(Q) P_{m}-\frac{b}{h+b}+P_{0} \\
& =\sum_{m=1}^{n} \emptyset_{X_{m}}^{(m)}(Q) P_{m}-\frac{b}{h+b}+P_{0}
\end{aligned}
$$




$$
\begin{aligned}
& +\left(1-\sum_{m=0}^{n} P_{m}\right)+\sum_{m=n+1}^{n+\infty} \emptyset_{X_{m}}^{(m)}(Q) P_{m} \\
& -\left(1-\sum_{m=0}^{n} P_{m}\right) \\
= & G\left(X_{m}, n\right)-\sum_{m=n+1}^{+\infty}\left[1-\emptyset_{X_{m}}^{(m)}(Q)\right] P_{m}
\end{aligned}
$$

Since $0 \leq 1-\emptyset_{X_{m}}^{(m)}(Q) \leq 1, \sum_{m=n+1}^{+\infty}\left[1-\emptyset_{X_{m}}^{(m)}(Q)\right] P_{m} \geq 0$. Thus $O\left(X_{m}\right) \leq G\left(X_{m}, n\right)$.

To sum up, $H\left(X_{m}, n\right) \leq O\left(X_{m}\right) \leq G\left(X_{m}, n\right)$.

Property 3. $H\left(X_{m}, n\right), O\left(X_{m}\right)$, and $G\left(X_{m}, n\right)$ are strictly increasing functions of $X_{m}$.

Proof. Since $H\left(X_{m}, n\right), O\left(X_{m}\right)$, and $G\left(X_{m}, n\right)$ are sums of varied cumulative probability distribution functions which are strictly increasing, these three functions are strictly increasing.

Property 4.

$$
\begin{aligned}
& \lim _{n \longrightarrow+\infty} G\left(X_{m}, n\right) \longrightarrow O\left(X_{m}\right), \\
& \lim _{n \longrightarrow+\infty} H\left(X_{m}, n\right) \longrightarrow O\left(X_{m}\right)
\end{aligned}
$$

Proof. When $\mathrm{n}$ tends to infinity, $\sum_{m=n}^{+\infty} \emptyset_{X_{m}}^{(m)}(Q) P_{m}$ and $\sum_{m=n+1}^{+\infty}\left[1-\emptyset_{X_{m}}^{(m)}(Q)\right] P_{m}$ tend to zero.

Assume that $Q_{L}, Q_{U}$, and $Q^{*}$ are the solutions of $G\left(X_{m}, n\right)=0, H\left(X_{m}, n\right)=0$, and $O\left(X_{m}\right)=0$, respectively. Based on the above three properties, the following Proposition 5 is correct when $\mathrm{n}$ tends to infinity.

Proposition 5. $Q^{*}$ can be approximated by an upper bound $Q_{U}$ and a lower bound $Q_{L}$ based on $Q_{L} \leq Q^{*} \leq Q_{U}$, where $Q_{U}$ is the solution of

$$
\begin{gathered}
\sum_{m=1}^{n} \emptyset_{X_{m}}^{(m)}(Q) \sum_{i=0}^{k-1} \frac{(k \lambda L)^{(k m+i)}}{(k m+i) !} e^{-k \lambda L} \\
=\frac{b}{h+b}-\sum_{i=0}^{k-1} \frac{(k \lambda L)^{(i)}}{i !} e^{-k \lambda L}
\end{gathered}
$$

and $Q_{L}$ is the solution of

$$
\begin{aligned}
\sum_{m=1}^{n} \emptyset_{X_{m}}^{(m)}(Q) \sum_{i=0}^{k-1} \frac{(k \lambda L)^{(k m+i)}}{(k m+i) !} e^{-k \lambda L} & \\
= & \frac{b}{h+b}-\sum_{i=0}^{k-1} \frac{(k \lambda L)^{(i)}}{i !} e^{-k \lambda L} \\
& -\left(1-\sum_{m=0}^{n}\left(\sum_{i=0}^{k-1} \frac{(k \lambda L)^{(k m+i)}}{(k m+i) !} e^{-k \lambda L}\right)\right)
\end{aligned}
$$

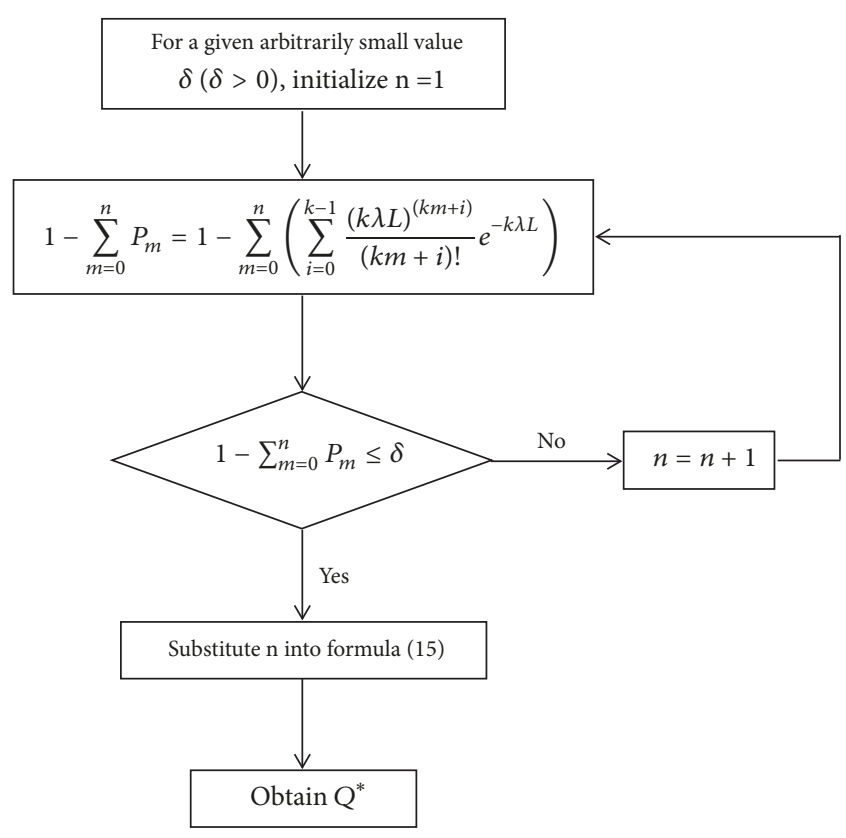

FIGURE 1: The flow chart of the basic algorithm.

3.3. Basic Algorithm. Based the above analysis, the algorithm to compute the optimal order quantity $Q^{*}$ is comprised the following steps.

Step 0 . For a given arbitrarily small value $\delta(\delta>0)$, initialize $n=1$.

Step 1. Compute $1-\sum_{m=0}^{n} P_{m}=1-\sum_{m=0}^{n}\left(\sum_{i=0}^{k-1}\left((k \lambda L)^{(k m+i)} /\right.\right.$ $\left.(k m+i) !) e^{-k \lambda L}\right)$.

Step 2

(i) If $1-\sum_{m=0}^{n} P_{m} \leq \delta$, go to Step 3 .

(ii) Otherwise do $n=n+1$ and go to Step 1 .

Step 3. Utilize the derived $\mathrm{n}$ to solve (15) so as to obtain $Q^{*}$.

Step 4. Stop.

In order to help understand the basic algorithm, all above procedures are illustrated in the flow chart, i.e., Figure 1.

In this flow chart, the optimal order quantity $Q^{*}$ is approximated by an upper bound $Q_{U}$ and a lower bound $Q_{L}$, both of which are calculated with finite varying $n$. As $n$ gets larger, the lower and upper bounds get tighter and the gap between them gets smaller. The algorithm cannot be stopped until the gap is smaller than the given stopping criterion $\delta$. In this circumstance, $Q_{L}$ is obtained by substituting the corresponding $n$ into formula (15), which is considered as an alternative to the optimal order quantity $Q^{*}$. In addition, it should be noted that $Q^{*}$ can be approximately as closely as desired by setting varied stopping criterion $\delta$. 


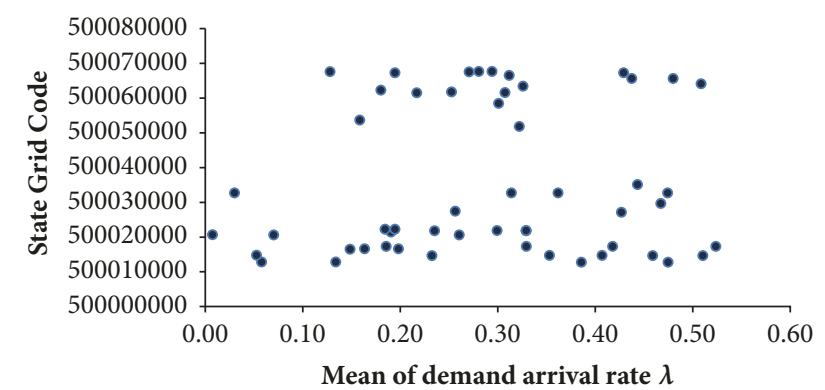

FIGURE 2: The scatter diagram of demand interarrival rate of electric power materials.

\section{Numerical Investigation}

4.1. Data Processing. There are 3,839 types of electric power materials in the State Grid Shanghai Electric Power Company. Because most of the 3,839 electrical power materials are relatively less important (e.g., circuits), we do not need to pay much attention to the inventory management for these electrical power materials with the model proposed in our paper. Moreover, for those electrical power materials which are also suitable for our model, some of them are not standardized and therefore eliminated (or are being eliminated). For standardized electrical power materials, due to similarity, only representative electrical power materials are selected. Thereby, we gather the historical data of demands of 53 types of electric power materials from 2015 to 2017, the demand arrivals of which follow an Erlang distribution in conjunction with a Gamma distribution of demand sizes. Since the Gamma distribution covers a large spectrum of probability distributions, such modelling is more appropriate. Basic information of the 53 types of electric power materials is presented in Table 1.

As shown in Table 1 , the mean nonzero demand sizes $\beta$ of the 53 types of electric power materials vary sharply, for example, the minimum mean nonzero demand size $\beta$ is 3.19 while the maximum mean nonzero demand size $\beta$ is 10437.16. Moreover, the variance of the mean nonzero demand size $\beta$ is 3041691. In a word, there exists a high volatility of mean nonzero demand size. And demand arrivals of the 53 types of electric power materials mostly follow a twostage Erlang distribution. There are only four electric power materials consisting of 500014661,500017325, 500020638 and 500064132 whose demand interarrivals follow three stage Erlang distribution.

Figure 2 shows the scatter diagram of demand arrival rate of the 53 types of electric power materials

As shown in Figure 2, the mean demand interarrival rate $\lambda$ of these 53 types of electric power materials within 3 years is between 0.01 and 0.52 , denoted by $\lambda \in[0.01,0.52]$. The variance of the mean demand interarrival rate $\lambda$ is 0.019 , reflecting its low volatility. According to the classification method proposed by Eaves [31], these electric power materials exhibit a high level of intermittence.

Subsequently, we adopt the above model to model the inventory cost of these materials, compute the optimal order

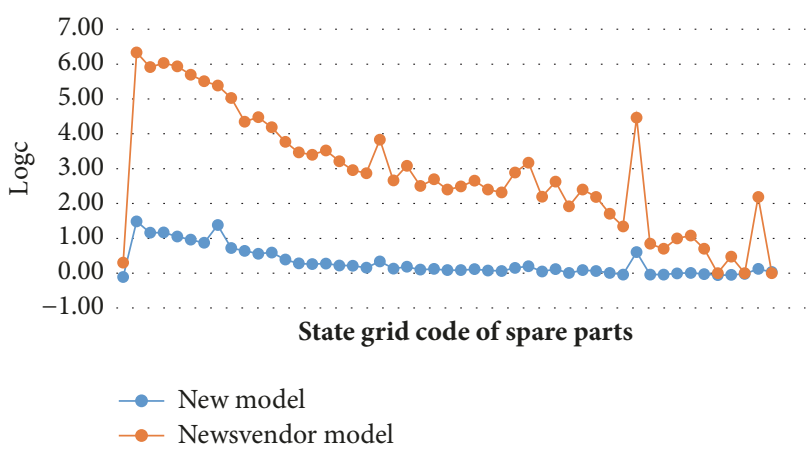

FIGURE 3: Average inventory costs calculated with the two models.

quantity of every electric power material and the corresponding average inventory cost and then compare them with results of the classic Newsvendor model (Trabka and Marchand [32]) to examine the validity of this method.

4.2. Comparison with the Newsvendor Model. The aim of this subsection is to examine the performance of the proposed theoretical model in cost reduction. We initially employed this new model to obtain the optimal order quantity of each electric power material and the corresponding average inventory cost and followed this with a comparison to the classic Newsvendor model under a Gamma demand process. Considering that the backordering cost is higher than the inventory holding cost, this paper assumes that $h=1, b=10$. Lead-time $L$ is assumed to be 1 . Results are as in Table 2 .

Table 2 illustrates the performances of the two models with respect to the optimal order quantity and inventory cost. Results show that the proposed theoretical model, i.e., new model suggests a higher optimal order quantity and lower average inventory cost compared with the Newsvendor model. Take the electric power material 500065644; for example, the optimal order quantity $Q$ obtained with the new model is 32, which is approximately 4.5 times of that obtained with the Newsvendor model which equals 7. However, in terms of average inventory cost $C$, the new model suggests a cost of 30.63 which is significantly less than that suggested by the Newsvendor model which equals 2162199. According to Table 2, other electric power materials show similar pattern as the above material 500065644.

In order to more vividly demonstrate the significant difference of average inventory cost $C$ between these two models, we make the line chart, i.e., Figure 3.

Since that there is huge gap between the average inventory cost $C$ calculated with the above two models, we use the natural logarithm of average inventory cost $C$ as the ordinate so as to narrow the gap. As shown in the Figure 3, the average inventory cost of new model is significantly less than that of Newsvendor model, which is consistent with the finding revealed by the Table 2 . In a word, larger optimal order quantity and lower average inventory cost are advised by the new model. The conflicting change in these two variables can be explained by the fact that although higher order quantity increases the amount of electric power materials kept in stock and thus holding cost, the backordering cost decreases due 
TABLE 1: Basic information of 53 types of electric power materials.

\begin{tabular}{|c|c|c|c|c|c|c|}
\hline State grid code of spare parts & Class & Division & Section & $\mathbf{k}$ & $\beta$ & $\lambda$ \\
\hline 500012723 & Hardware & Mechanical hardware & Bolt & 2 & 2137.77 & 0.47 \\
\hline 500012771 & Hardware & Mechanical hardware & Bolt & 2 & 840.70 & 0.39 \\
\hline 500012797 & Hardware & Mechanical hardware & Bolt & 2 & 352.31 & 0.06 \\
\hline 500012801 & Hardware & Mechanical hardware & Bolt & 2 & 118.76 & 0.13 \\
\hline 500014661 & Installation & Wire & Aerial insulation wire & 3 & 9.47 & 0.51 \\
\hline 500014662 & Installation & Wire & Aerial insulation wire & 2 & 14.37 & 0.23 \\
\hline 500014670 & Installation & Wire & Aerial insulation wire & 2 & 37.59 & 0.46 \\
\hline 500014711 & Installation & Wire & Aerial insulation wire & 2 & 5.18 & 0.41 \\
\hline 500014713 & Installation & Wire & Aerial insulation wire & 2 & 4.53 & 0.35 \\
\hline 500014805 & Installation & Cable & Cloth wire & 2 & 10437.16 & 0.05 \\
\hline 500016589 & Installation & Cable & Control cable & 2 & 1161.67 & 0.20 \\
\hline 500016592 & Installation & Cable & Control cable & 2 & 1080.33 & 0.16 \\
\hline 500017293 & Installation & Insulator & Post porcelain insulator & 2 & 254.76 & 0.33 \\
\hline 500017320 & Installation & Insulator & Strain insulator & 2 & 279.17 & 0.19 \\
\hline 500017324 & Installation & Fitting & Shackle insulator & 2 & 6474.62 & 0.42 \\
\hline 500017325 & Installation & Fitting & Shackle insulator & 3 & 1849.46 & 0.52 \\
\hline 500020609 & Installation & Cable accessories & Splicing fitting-GT-G & 2 & 27.05 & 0.26 \\
\hline 500020612 & Installation & Cable accessories & Splicing fitting-GT-G & 2 & 3091.22 & 0.07 \\
\hline 500020638 & Installation & Cable accessories & Splicing fitting-GTL & 3 & 22.04 & 0.01 \\
\hline 500021412 & Installation & Cable accessories & $35 \mathrm{kV}$ cable connector & 2 & 6.64 & 0.19 \\
\hline 500021803 & Installation & Cable accessories & Cable terminals & 2 & 79.97 & 0.24 \\
\hline 500021830 & Installation & Low voltage apparatus & Cable terminals & 2 & 280.81 & 0.33 \\
\hline 500021862 & Installation & Low voltage apparatus & Cable terminals & 2 & 1363.48 & 0.30 \\
\hline 500021869 & Installation & Surge arrester & Cable terminals & 2 & 305.76 & 0.33 \\
\hline 500022269 & Low voltage apparatus & Traverse, earth wire & Low-tension fuse & 2 & 218.86 & 0.19 \\
\hline 500022271 & Low voltage apparatus & Fitting & Low-tension fuse & 2 & 2293.08 & 0.18 \\
\hline 500027151 & Primary equipment & High-pressure fuse fittings & AC surge arrester & 2 & 210.94 & 0.43 \\
\hline 500027464 & Installation & High-tension fuse accessories & Aerial insulation traverse & 2 & 5.05 & 0.26 \\
\hline 500029690 & Installation & High-tension fuse accessories & Guy wire fitting-wedge clamps & 2 & 280.30 & 0.47 \\
\hline 500032681 & Spare part & High-tension fuse accessories & Fuse & 2 & 85.64 & 0.31 \\
\hline 500032682 & Spare part & Iron fittings & Fuse & 2 & 27.35 & 0.03 \\
\hline 500032684 & Spare part & Mechanical hardware & Fuse & 2 & 151.88 & 0.47 \\
\hline 500032687 & Spare part & Cable accessories & Fuse & 2 & 60.44 & 0.36 \\
\hline 500035137 & Installation & Mechanical hardware & Anchor rod & 2 & 250.67 & 0.44 \\
\hline 500051829 & Hardware & Low voltage apparatus & Bolt & 2 & 349.51 & 0.32 \\
\hline 500053694 & Installation & Low voltage apparatus & $35 \mathrm{kV}$ cable termination & 2 & 8.26 & 0.16 \\
\hline 500058470 & Hardware & Security burglary fire & Bolt & 2 & 1547.98 & 0.30 \\
\hline 500061526 & Low voltage apparatus & Security burglary fire & Low-tension fuse accessories & 2 & 131.57 & 0.22 \\
\hline 500061564 & Low voltage apparatus & Fitting & Low-tension fuse accessories & 2 & 113.72 & 0.31 \\
\hline 500061758 & Supplementary equipment & Fitting & Anti-lighting device & 2 & 211.26 & 0.25 \\
\hline 500062282 & Supplementary equipment & Traverse, earth wire & Anti-lighting device & 2 & 163.65 & 0.18 \\
\hline 500063419 & Installation & Traverse, earth wire & Strain clamps-pre-twisted type & 2 & 166.65 & 0.33 \\
\hline 500064132 & Installation & Iron fittings & Guy wire fittings-guy clips & 3 & 1465.33 & 0.51 \\
\hline 500065644 & Installation & Mechanical hardware & Aerial insulation traverse & 2 & 3.19 & 0.48 \\
\hline 500065658 & Installation & Mechanical hardware & Aerial insulation traverse & 2 & 31.22 & 0.44 \\
\hline 500066495 & Installation & Fittings & Iron connection & 2 & 2827.08 & 0.31 \\
\hline 500067251 & Hardware & Iron fittings & Bolt & 2 & 352.50 & 0.19 \\
\hline 500067292 & Hardware & Iron fittings & Bolt & 2 & 469.55 & 0.43 \\
\hline 500067551 & Installation & Iron fittings & Guy wire fittings-guy clips & 2 & 581.01 & 0.27 \\
\hline
\end{tabular}


TABle 1: Continued.

\begin{tabular}{|c|c|c|c|c|c|c|}
\hline State grid code of spare parts & Class & Division & Section & $\mathbf{k}$ & $\beta$ & $\lambda$ \\
\hline 500067567 & Installation & Description of the class & Cable hold hoop & 2 & 56.25 & 0.13 \\
\hline 500067652 & Installation & Mechanical hardware & Semicircular hold hoop & 2 & 92.10 & 0.28 \\
\hline 500067654 & Installation & Mechanical hardware & Semicircular hold hoop & 2 & 202.46 & 0.29 \\
\hline 500016521 & Installation & Mechanical hardware & Control cable & 2 & 576.27 & 0.15 \\
\hline
\end{tabular}

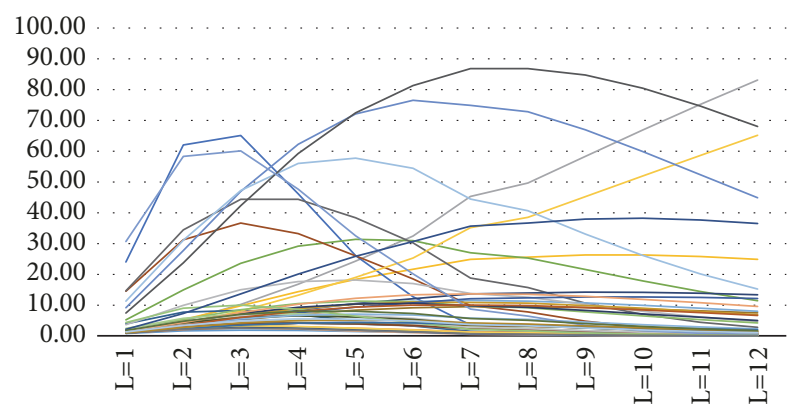

FIgURE 4: The average inventory $\operatorname{cost} C$ with varying lead time $L$ for the electric power materials with compound Erlang-distributed demand.

to the less unfilled demand, leading to a reduction in total inventory cost. Thus the new model outperforms the classic Newsboy model in cost reductions, which is more suitable for cost-oriented inventory system

4.3. Sensitivity Analysis of Lead Time. In this subsection, we vary the value of lead time $L$ in order to analyze its impacts on the average inventory cost $C$. Thus we consider the various values of lead time $\mathrm{L}$ in the interval $[1,10]$ and compute the corresponding average inventory cost $C$ respectively. The outcomes are shown in Table 3 and Figure 4.

As shown in the Table 3, an overwhelming percent of electric power materials with compound Erlang-distributed demand demonstrates a nonliner relationship between lead time $L$ and average inventory cost $C$. Specifically speaking, as lead time $L$ increases, the average inventory cost $C$ of most electric power material rises first and then falls. For example, for electric power material 500012723, the corresponding average inventory cost $C$ experiences an increase from 0.78 to 1.88 as the lead time $L$ increases from 1 to 3 . After reaching its peak of 1.88 , the average inventory cost begins to decrease and reaches 0.29 when lead time is 10 .

In order to more vividly depict the effect of lead time on the average inventory cost, we make the line chart in Figure 4 based on Table 3 .

Figure 4 illustrates that, for most electric power material with compound Erlang-distributed demand, average inventory cost initially rises in the lead time and subsequently this trend reverses. However, there are three types of electric power material such as 500012797, 500020612, and 500032682 which do not show the above relationship. Instead, the average inventory cost rises with the lead time. Maybe it is because that the lead time is not large enough. If lead time is larger, the corresponding inventory cost maybe will provide the same pattern as the other most electric power material with compound Erlang-distributed demand.

\section{The Approximation and Heuristic Algorithm}

Given the complexity of the basic algorithm, this paper proposes easily implementable approximation and heuristic algorithms for determining the optimal order quantity under the $(T, Q)$ policy. These two methods simplify complicated mathematical calculation and solve the lot-sizing problem, which are of great utility in the real industrial context.

5.1. The Approximation Algorithm. This paper proposes an approximation algorithm to determine the optimal order quantity by seeking the minimum iterative numbers within the desired accuracy under the varied average demand interarrival rate $\lambda$ and average nonzero demand size $\beta$. Thus, the calculation process is simplified due to reduced iterative numbers. Electric power materials vary with the iterative number corresponding to the optimal order quantity in this proposed model. If practitioners control material inventory and determine the optimal order quantity based on the above iterative numbers, the efficiency of inventory management will be rather low due to the wide range of electric power materials. Therefore, if the iterative number can be reduced while guaranteeing accuracy, the simplification can significantly increase companies' efficiency.

Calculation is as follows.

Step 1. Adopt the basic algorithm to calculate the optimal iterative numbers of each electric power material with different $\lambda, \beta, k$.When the value of $1-\sum_{m=0}^{n} P_{m}$ in formula (15) converges to zero, the right side of formula (14) and (15) is almost equal. The corresponding iterative number is the optimal, denoted by $n^{*}$. We assumed that the optimal iterative number $n^{*}$ is derived when $\delta$ equals $10^{-4}$ or equivalently $1-\sum_{m=0}^{n} P_{m} \leq 10^{-4}$.

Step 2. Calculate the corresponding optimal order quantity $Q^{*}$.

Step 3. Calculate the effective iterative number within the acceptable error range, denoted by $\tilde{n}$. We assume that the acceptable error range is $10 \%$.

The effective iterative number $\tilde{n}$ is derived as in Figure 5.

In this flow chart, $Q^{*}$ and $\tilde{n}$ are derived by comparing the corresponding order quantity $Q_{n}$ with optimal order quantity $Q^{*}$. This algorithm can be stopped when the difference between $Q_{n}$ and $Q^{*}$ is small enough and conforms to the 
TABLE 2: The optimal order quantity and corresponding average inventory cost of the two methods.

\begin{tabular}{|c|c|c|c|c|}
\hline \multirow{2}{*}{$\begin{array}{l}\text { State grid code of } \\
\text { materials }\end{array}$} & \multicolumn{2}{|c|}{ Optimal order quantity $Q$} & \multicolumn{2}{|c|}{ Average inventory cost $C$} \\
\hline & New model & Newsvendor model & New model & Newsvendor model \\
\hline 500012723 & 7475 & 4697 & 0.78 & 2 \\
\hline 500012771 & 3669 & 1847 & 0.91 & 22 \\
\hline 500012797 & 935 & 774 & 1.32 & 154 \\
\hline 500012801 & 613 & 261 & 1.59 & 1490 \\
\hline 500014661 & 77 & 21 & 24.03 & 244424 \\
\hline 500014662 & 116 & 32 & 5.23 & 106020 \\
\hline 500014670 & 283 & 83 & 3.91 & 15360 \\
\hline 500014711 & 50 & 11 & 14.51 & 819737 \\
\hline 500014713 & 44 & 10 & 14.65 & 1069736 \\
\hline 500016589 & 3987 & 2552 & 0.99 & 10 \\
\hline 500016592 & 3506 & 2374 & 1.02 & 12 \\
\hline 500017293 & 1392 & 560 & 1.22 & 307 \\
\hline 500017320 & 1332 & 613 & 1.22 & 253 \\
\hline 500017325 & 5282 & 4064 & 0.89 & 3 \\
\hline 500020609 & 203 & 59 & 3.63 & 29781 \\
\hline 500020612 & 2557 & 6792 & 1.08 & 1 \\
\hline 500021412 & 57 & 15 & 9.11 & 498517 \\
\hline 500021803 & 505 & 176 & 1.89 & 3338 \\
\hline 500021830 & 1507 & 617 & 1.19 & 250 \\
\hline 500021862 & 5069 & 2996 & 0.91 & 7 \\
\hline 500021869 & 1615 & 672 & 1.16 & 209 \\
\hline 500022269 & 1111 & 481 & 1.30 & 422 \\
\hline 500022271 & 6100 & 5038 & 0.96 & 1 \\
\hline 500027151 & 1219 & 463 & 1.35 & 455 \\
\hline 500027464 & 47 & 11 & 11.33 & 863026 \\
\hline 500029690 & 1541 & 616 & 1.22 & 251 \\
\hline 500032681 & 559 & 188 & 1.91 & 2904 \\
\hline 500032682 & 110 & 60 & 4.02 & 29123 \\
\hline 500032684 & 930 & 334 & 1.64 & 899 \\
\hline 500032687 & 421 & 133 & 2.45 & 5889 \\
\hline 500035137 & 1408 & 551 & 1.26 & 317 \\
\hline 500051829 & 1794 & 768 & 1.12 & 157 \\
\hline 500053694 & 67 & 18 & 7.43 & 321886 \\
\hline 500058470 & 5567 & 3401 & 0.91 & 5 \\
\hline 500061526 & 753 & 289 & 1.52 & 1208 \\
\hline 500061564 & 707 & 250 & 1.67 & 1629 \\
\hline 500061758 & 1145 & 464 & 1.30 & 454 \\
\hline 500062282 & 862 & 360 & 1.41 & 771 \\
\hline 500063419 & 980 & 366 & 1.43 & 743 \\
\hline 500064132 & 4528 & 3220 & 0.94 & 5 \\
\hline 500065644 & 32 & 7 & 30.63 & 2162199 \\
\hline 500065658 & 240 & 69 & 4.39 & 22318 \\
\hline 500066495 & 8558 & 6212 & 0.88 & 1 \\
\hline 500067251 & 1622 & 775 & 1.16 & 154 \\
\hline 500067292 & 2340 & 1032 & 1.01 & 83 \\
\hline
\end{tabular}


TABLE 2: Continued.

\begin{tabular}{lcccc}
\hline $\begin{array}{l}\text { State grid code of } \\
\text { materials }\end{array}$ & \multicolumn{2}{c}{ Optimal order quantity Q } & \multicolumn{2}{c}{ Average inventory cost C } \\
Newsvendor model \\
\hline 500067551 & New model & Newsvendor model & New model & 1.02 \\
500067567 & 2601 & 1277 & 2.18 & 6809 \\
500067652 & 329 & 124 & 1.81 & 2505 \\
500067654 & 585 & 202 & 1.32 & 496 \\
\hline
\end{tabular}

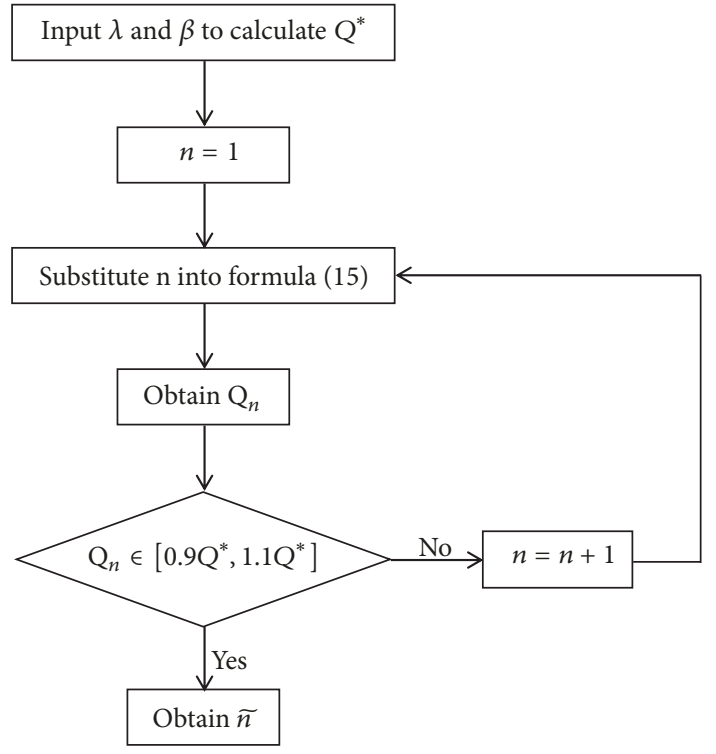

FIgURE 5: The flow chart of calculation of $\tilde{n}$ under the approximation approach.

predefined criterion. The effective iterative number $\widetilde{n}$ is thus obtained.

Based on the above approximation algorithm, $Q^{*}$ and $\widetilde{n}$ under varied $\lambda, \beta, \mathrm{k}$ are calculated and the results are shown in Appendices A and B (Figures 7 and 8 correspond to the result of $\tilde{n}$ and Figures 9 and 10 correspond to the result of $\left.Q^{*}\right)$. It reveals that there is an overwhelming percentage of electric power materials whose effective iterative numbers $\widetilde{n}$ equal 2, while the effective iterative number for the remaining electric power materials is 1 . This means, for most electric power material, the approximately optimal order quantity $Q^{*}$ can be derived after only two iterations under the acceptable error range of 10 percent. Given the positive relationships between the accuracy and the number of iterations, the uniform iterative number for all electric power materials of electric power companies with a compound Erlang-k demand distribution is set to be 2 . Thus practitioners can calculate the order quantity through two iterations for all electric power material with compound Erlang-distributed demand.

5.2. The Heuristic Algorithm. Given the complexity of the basic algorithm and the shortage of relevant experts in enterprises, this paper proposes a more implementable heuristic algorithm. This algorithm attempts to generalize the relationship between average demand interarrival rate $\lambda$ and the optimal order quantity $Q^{*}$ for varied $\beta$ and $\mathrm{k}$. In this paper, we utilize the scatter diagrams to illustrate their relationships in the cases of $k$ is equal to 2 and 3.

When $\mathrm{k}=2$, the relationships between the independent variable $\lambda$ and the dependent variable $Q^{*}$ under varied $\beta$ are as in Figure 6.

Because of space constraints, the relationships between $\lambda$ and $Q^{*}$ with respect to varied $\beta$ when $\mathrm{k}=3$ are shown in the Figure 11 which is put in Appendix C.

As shown in Figures 6 and 11, the optimal quantity $Q^{*}$ also increases when the average demand arrival rate $\lambda$ increases. As $\lambda$ increases, i.e., the intermittence get weaker, the optimal order quantity $Q^{*}$ increases. Such relationship implies that for electric power materials whose demand exhibits a higher intermittence, it is more economic for organizations to experience stock-outs occasionally than to keep high quantities in stock. Moreover, as $\lambda$ rises, the optimal order quantity tends to be deterministic. In addition, keeping $\lambda$ constant, the optimal order quantity $Q^{*}$ grows with the mean nonnegative demand sizes $\beta$. Moreover, the optimal order quantity $Q^{*}$ also increases with $\mathrm{k}$. As $k$ increases, i.e., the degree of certainty on demand arrival increases, the order quantity increases. For instance, when $\beta$ is 500 and $\lambda$ is 0.5 , the optimal order quantity $Q^{*}$ is from 750 to 3000 , respectively, when $k$ shifts from 2 to 3 .

Based on the above analysis, the relationships between $\lambda$ and $Q^{*}$ can be generalized as

$$
\mathrm{Q}^{*}=c-\mathrm{e}^{-\mathrm{a} \lambda} \quad(a \geq 0)
$$

Subsequently, we employ the calculated $\lambda$ and $Q^{*}$ as inputs to determine parameters $c$ and $a$, followed by an analysis of accuracy. Results are as in Table 4.

As the average demand sizes $\beta$ increases, the parameter $c$ increases obviously while the parameter $a$ remains relatively stable. When $\lambda$ is very small, i.e., demand interval $\mathrm{T}$ is large, the optimal order quantity $Q^{*}$ is approximately equal to parameter $c$. In this case, when average demand size is large, coupled with long demand interval, organizations will order more quantity to satisfy the large demand, leading to the rise in parameter $c$. This is the reason why $c$ grows with $\beta$. Moreover, parameters $c$ and $a$ decrease when $k$ increases; i.e., the certainty degree on demand arrivals increases. In addition, MAPE is computed to examine the goodness of fit of these relationships to real data. The value of MAPE is mostly around $15 \%$, indicating that this algorithm is effective in the practical application. Moreover, MAPE gets larger with 
TABLE 3: Average inventory cost $C$ of varying lead time $L$ for the electric power materials with compound Erlang distributed demand.

\begin{tabular}{|c|c|c|c|c|c|c|c|c|c|c|}
\hline \multirow{2}{*}{ State grid code of materials } & \multicolumn{10}{|c|}{ Average inventory cost $\mathrm{C}$} \\
\hline & $\mathrm{L}=\mathbf{1}$ & $\mathrm{L}=\mathbf{2}$ & $\mathrm{L}=3$ & $\mathrm{~L}=4$ & $\mathbf{L}=5$ & $\mathrm{~L}=6$ & $\mathrm{~L}=7$ & $\mathrm{~L}=\mathbf{8}$ & $\mathrm{L}=9$ & $\mathrm{~L}=\mathbf{1 0}$ \\
\hline 500012723 & 0.78 & 1.61 & 1.88 & 1.75 & 1.46 & 1.13 & 0.71 & 0.60 & 0.42 & 0.29 \\
\hline 500012771 & 0.91 & 2.08 & 2.65 & 2.64 & 2.30 & 1.85 & 1.21 & 1.03 & 0.73 & 0.51 \\
\hline 500012797 & 1.32 & 4.89 & 10.19 & 16.79 & 24.31 & 32.46 & 45.31 & 49.66 & 58.34 & 66.88 \\
\hline 500012801 & 1.59 & 5.28 & 9.81 & 14.35 & 18.38 & 21.65 & 24.90 & 25.56 & 26.29 & 26.33 \\
\hline 500014661 & 24.03 & 62.03 & 65.13 & 46.20 & 26.11 & 12.70 & 3.57 & 2.25 & 0.86 & 0.31 \\
\hline 500014662 & 5.23 & 14.90 & 23.58 & 29.15 & 31.40 & 30.93 & 27.04 & 25.29 & 21.55 & 17.84 \\
\hline 500014670 & 3.91 & 7.74 & 8.31 & 6.88 & 4.92 & 3.20 & 1.49 & 1.13 & 0.63 & 0.34 \\
\hline 500014711 & 14.51 & 31.23 & 36.63 & 33.20 & 26.00 & 18.52 & 9.88 & 7.82 & 4.77 & 2.82 \\
\hline 500014713 & 14.65 & 34.44 & 44.39 & 44.35 & 38.38 & 30.25 & 18.82 & 15.69 & 10.62 & 6.97 \\
\hline 500016589 & 0.99 & 3.02 & 5.17 & 7.00 & 8.33 & 9.14 & 9.54 & 9.49 & 9.21 & 8.73 \\
\hline 500016592 & 1.02 & 3.26 & 5.87 & 8.36 & 10.48 & 12.11 & 13.63 & 13.92 & 14.20 & 14.16 \\
\hline 500017293 & 1.22 & 3.02 & 4.11 & 4.36 & 4.02 & 3.40 & 2.37 & 2.06 & 1.51 & 1.08 \\
\hline 500017320 & 1.22 & 3.76 & 6.47 & 8.75 & 10.35 & 11.25 & 11.48 & 11.32 & 10.74 & 9.93 \\
\hline 500017325 & 0.89 & 2.46 & 3.08 & 2.94 & 2.48 & 1.98 & 1.31 & 1.13 & 0.82 & 0.58 \\
\hline 500020609 & 3.63 & 9.92 & 15.00 & 17.68 & 18.15 & 17.02 & 13.81 & 12.59 & 10.20 & 8.03 \\
\hline 500020612 & 1.08 & 3.93 & 8.10 & 13.23 & 19.03 & 25.28 & 35.15 & 38.51 & 45.25 & 51.98 \\
\hline 500021412 & 9.11 & 27.71 & 46.94 & 62.28 & 72.13 & 76.53 & 74.93 & 72.80 & 66.98 & 59.92 \\
\hline 500021803 & 1.89 & 5.37 & 8.48 & 10.47 & 11.28 & 11.12 & 9.74 & 9.12 & 7.79 & 6.48 \\
\hline 500021830 & 1.19 & 2.93 & 3.99 & 4.25 & 3.93 & 3.33 & 2.33 & 2.03 & 1.49 & 1.07 \\
\hline 500021862 & 0.91 & 2.41 & 3.56 & 4.14 & 4.24 & 4.01 & 3.36 & 3.11 & 2.61 & 2.15 \\
\hline 500021869 & 1.16 & 2.86 & 3.90 & 4.15 & 3.85 & 3.27 & 2.30 & 2.00 & 1.48 & 1.06 \\
\hline 500022269 & 1.30 & 3.93 & 6.66 & 8.85 & 10.30 & 10.99 & 10.89 & 10.63 & 9.90 & 8.97 \\
\hline 500022271 & 0.96 & 3.02 & 5.36 & 7.53 & 9.35 & 10.74 & 12.07 & 12.33 & 12.62 & 12.66 \\
\hline 500027151 & 1.35 & 2.84 & 3.26 & 2.92 & 2.26 & 1.60 & 0.85 & 0.68 & 0.42 & 0.25 \\
\hline 500027464 & 11.33 & 31.10 & 47.26 & 56.03 & 57.78 & 54.46 & 44.48 & 40.65 & 33.07 & 26.12 \\
\hline 500029690 & 1.22 & 2.42 & 2.61 & 2.19 & 1.59 & 1.06 & 0.52 & 0.40 & 0.23 & 0.13 \\
\hline 500032681 & 1.91 & 4.80 & 6.65 & 7.17 & 6.72 & 5.75 & 4.06 & 3.54 & 2.61 & 1.88 \\
\hline 500032682 & 4.02 & 15.43 & 33.35 & 56.92 & 85.37 & 117.99 & 173.30 & 193.13 & 234.49 & 277.68 \\
\hline 500032684 & 1.64 & 3.18 & 3.36 & 2.74 & 1.94 & 1.25 & 0.58 & 0.44 & 0.24 & 0.13 \\
\hline 500032687 & 2.45 & 5.69 & 7.25 & 7.17 & 6.14 & 4.80 & 2.96 & 2.46 & 1.65 & 1.08 \\
\hline 500035137 & 1.26 & 2.59 & 2.90 & 2.53 & 1.91 & 1.32 & 0.68 & 0.53 & 0.32 & 0.19 \\
\hline 500051829 & 1.12 & 2.79 & 3.86 & 4.17 & 3.92 & 3.38 & 2.43 & 2.13 & 1.61 & 1.18 \\
\hline 500053694 & 7.43 & 23.73 & 42.31 & 59.23 & 72.48 & 81.35 & 86.83 & 86.86 & 84.77 & 80.47 \\
\hline 500058470 & 0.91 & 2.39 & 3.53 & 4.12 & 4.24 & 4.03 & 3.41 & 3.16 & 2.68 & 2.22 \\
\hline 500061526 & 1.52 & 4.45 & 7.26 & 9.27 & 10.33 & 10.56 & 9.77 & 9.32 & 8.28 & 7.15 \\
\hline 500061564 & 1.67 & 4.24 & 5.94 & 6.49 & 6.16 & 5.35 & 3.87 & 3.40 & 2.55 & 1.86 \\
\hline 500061758 & 1.30 & 3.60 & 5.55 & 6.70 & 7.05 & 6.80 & 5.78 & 5.35 & 4.49 & 3.67 \\
\hline 500062282 & 1.41 & 4.38 & 7.58 & 10.30 & 12.25 & 13.36 & 13.68 & 13.51 & 12.84 & 11.89 \\
\hline 500063419 & 1.43 & 3.52 & 4.80 & 5.10 & 4.71 & 3.97 & 2.76 & 2.39 & 1.75 & 1.24 \\
\hline 500064132 & 0.94 & 2.63 & 3.29 & 3.07 & 2.52 & 1.93 & 1.21 & 1.02 & 0.72 & 0.49 \\
\hline 500065644 & 30.63 & 58.31 & 60.09 & 47.63 & 32.54 & 20.18 & 8.72 & 6.43 & 3.40 & 1.75 \\
\hline 500065658 & 4.39 & 9.00 & 10.03 & 8.63 & 6.41 & 4.34 & 2.14 & 1.65 & 0.96 & 0.54 \\
\hline 500066495 & 0.88 & 2.32 & 3.47 & 4.12 & 4.33 & 4.24 & 3.77 & 3.57 & 3.15 & 2.73 \\
\hline 500067251 & 1.16 & 3.52 & 5.98 & 7.98 & 9.33 & 10.01 & 10.03 & 9.83 & 9.23 & 8.44 \\
\hline 500067292 & 1.01 & 2.14 & 2.50 & 2.27 & 1.80 & 1.30 & 0.73 & 0.59 & 0.37 & 0.23 \\
\hline 500067551 & 1.02 & 2.79 & 4.22 & 5.01 & 5.20 & 4.97 & 4.18 & 3.87 & 3.24 & 2.64 \\
\hline 500067567 & 2.18 & 7.27 & 13.62 & 20.06 & 25.89 & 30.69 & 35.64 & 36.70 & 37.97 & 38.24 \\
\hline 500067652 & 1.81 & 4.80 & 7.03 & 8.03 & 7.99 & 7.27 & 5.64 & 5.06 & 3.99 & 3.05 \\
\hline 500067654 & 1.32 & 3.43 & 4.93 & 5.54 & 5.43 & 4.86 & 3.69 & 3.30 & 2.57 & 1.94 \\
\hline
\end{tabular}



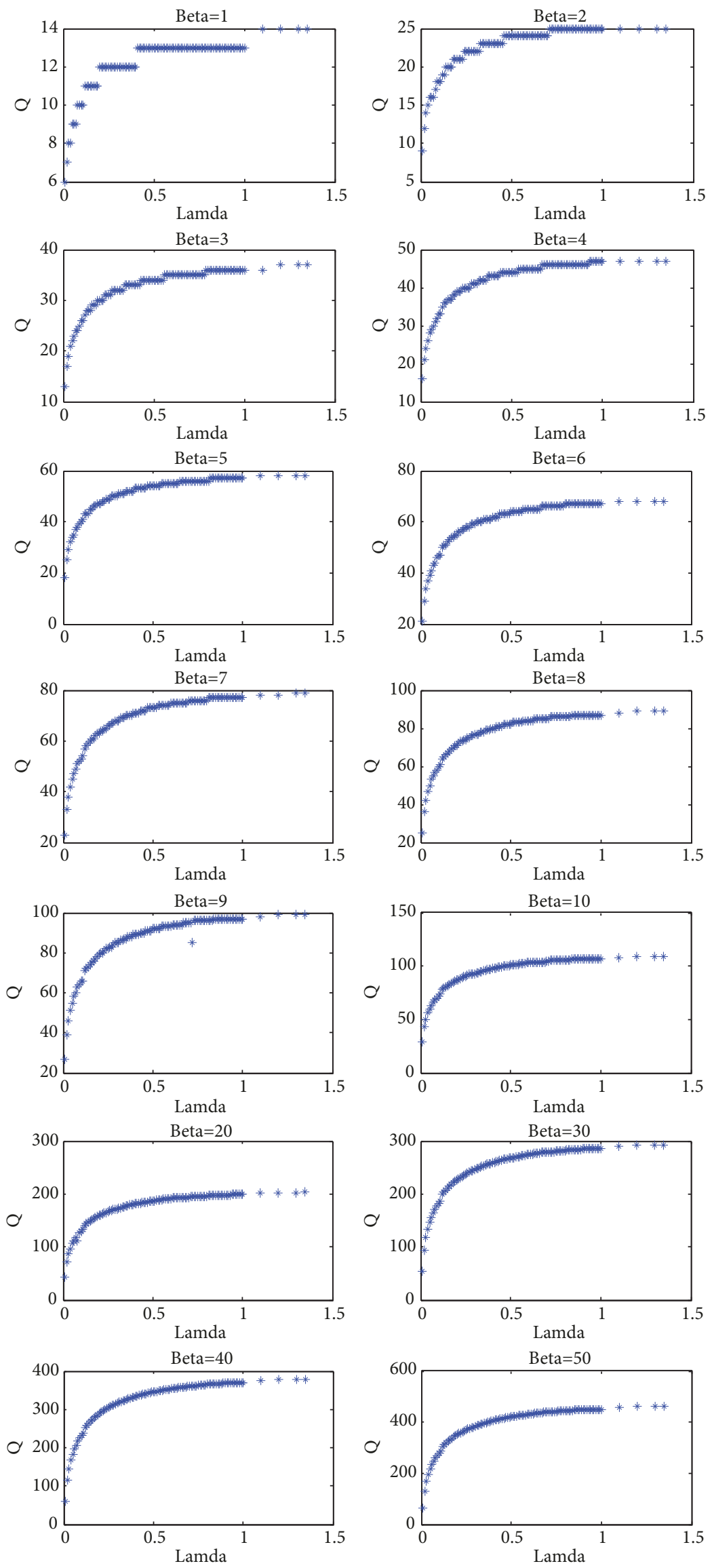

Figure 6: Continued. 

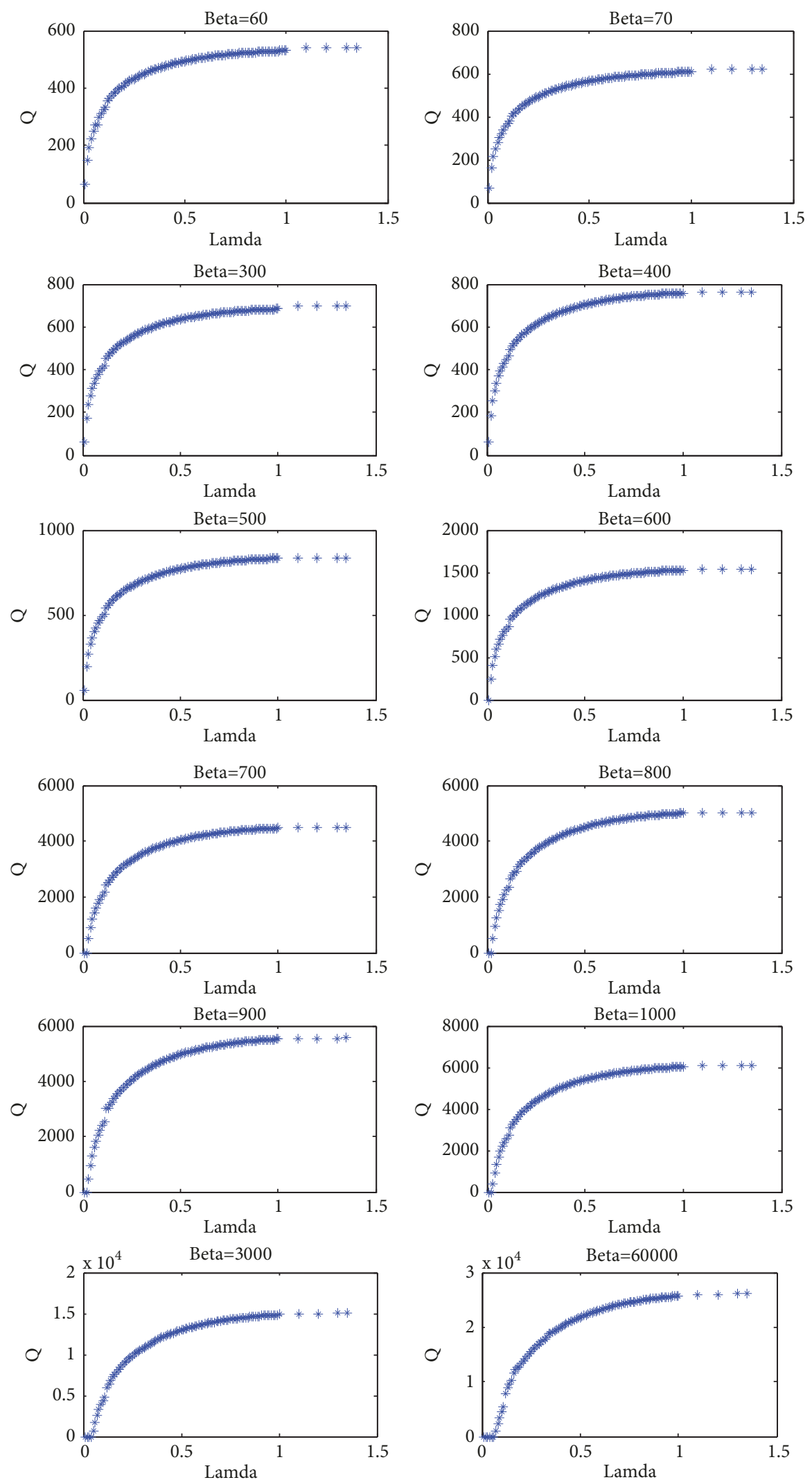

FIgURE 6: The relationships between $\lambda$ and $Q^{*}$ with respect to varied $\beta$ when $k=2$. 


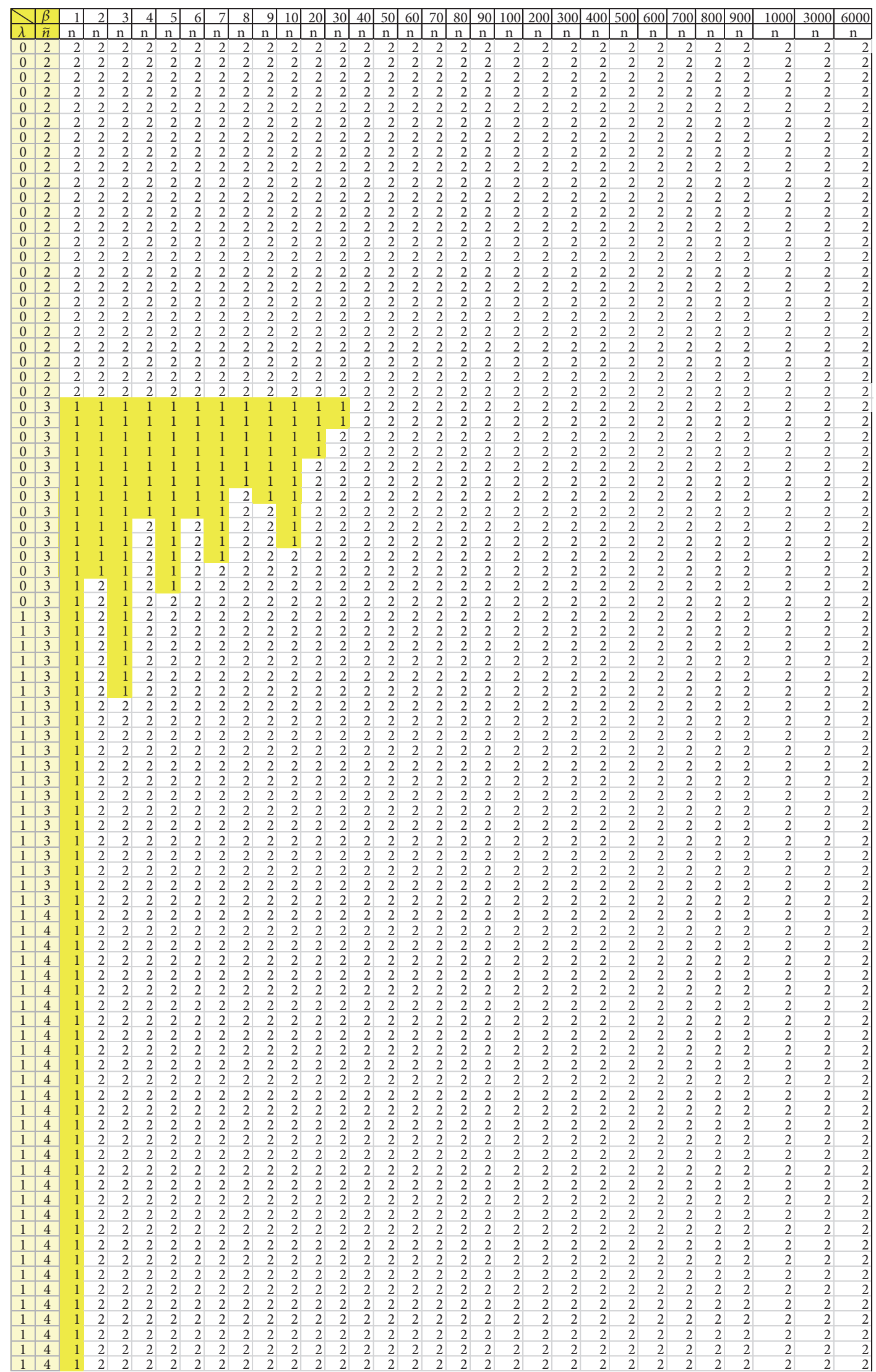

Figure 7: $\tilde{n}$ under varied $\lambda, \beta$ when $k=2$. 


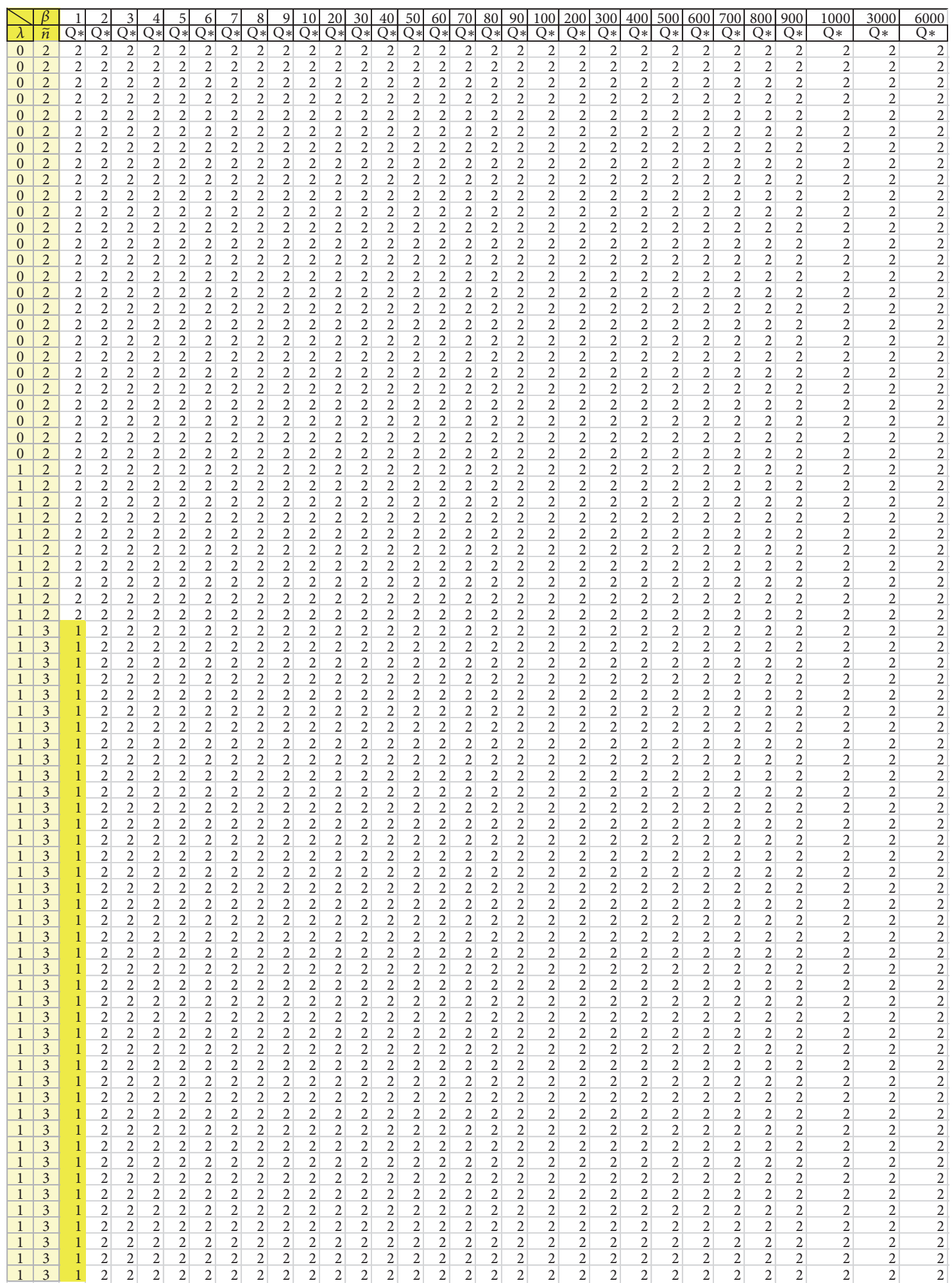

FIGURE 8: $\widetilde{n}$ under varied $\lambda, \beta$ when $k=3$.

the increases of the mean demand sizes $\beta$ and the number of stages $\mathrm{k}$, implying that this algorithm is more suitable for those electric power materials whose demand size is not large and demand arrivals follow two-stage Erlang distribution.

\section{Conclusion and Future Research}

Currently, the compound Poisson distribution is the most often utilized model for intermittent demand to control 


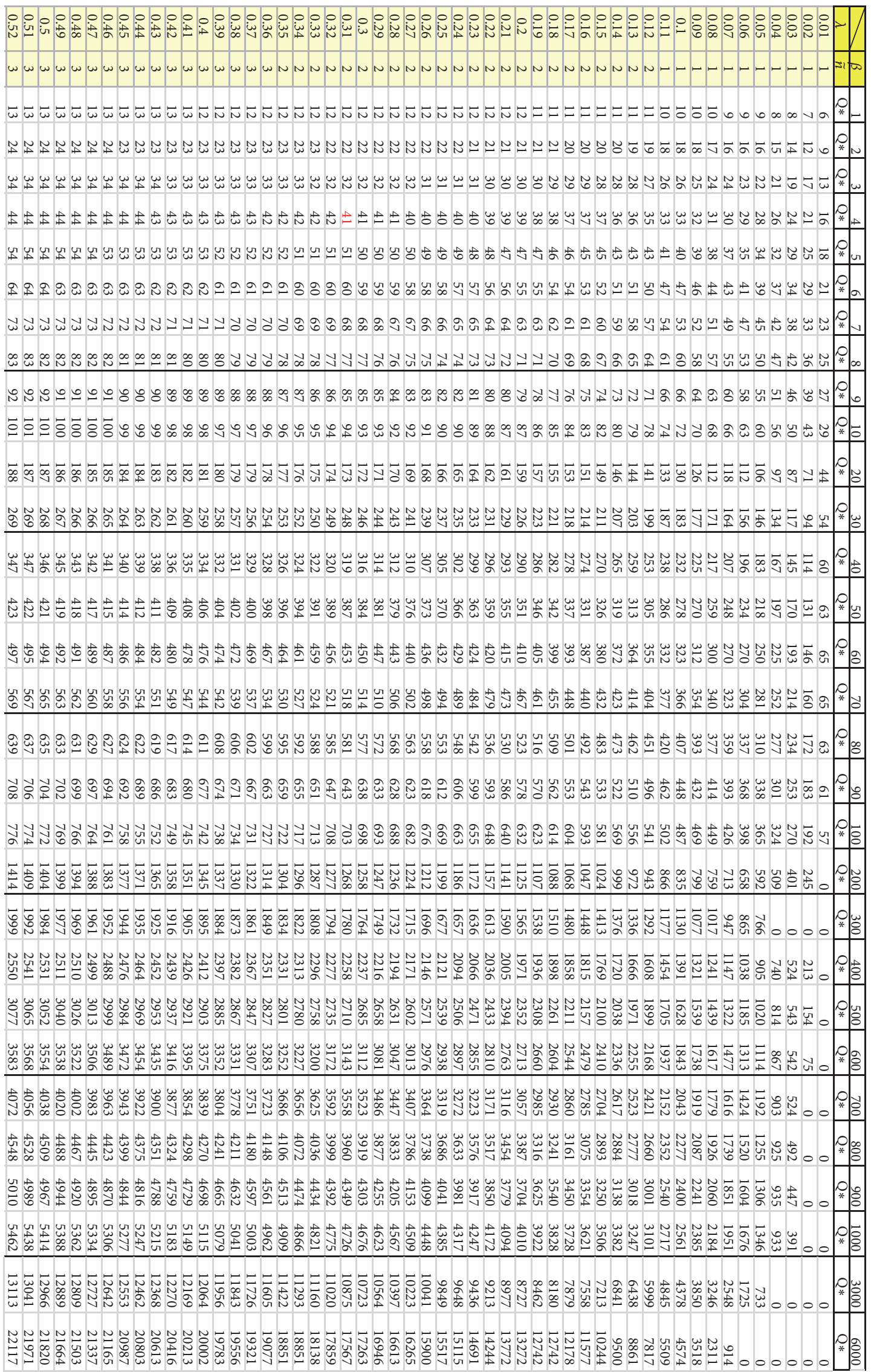

FIGURE 9: Continued. 


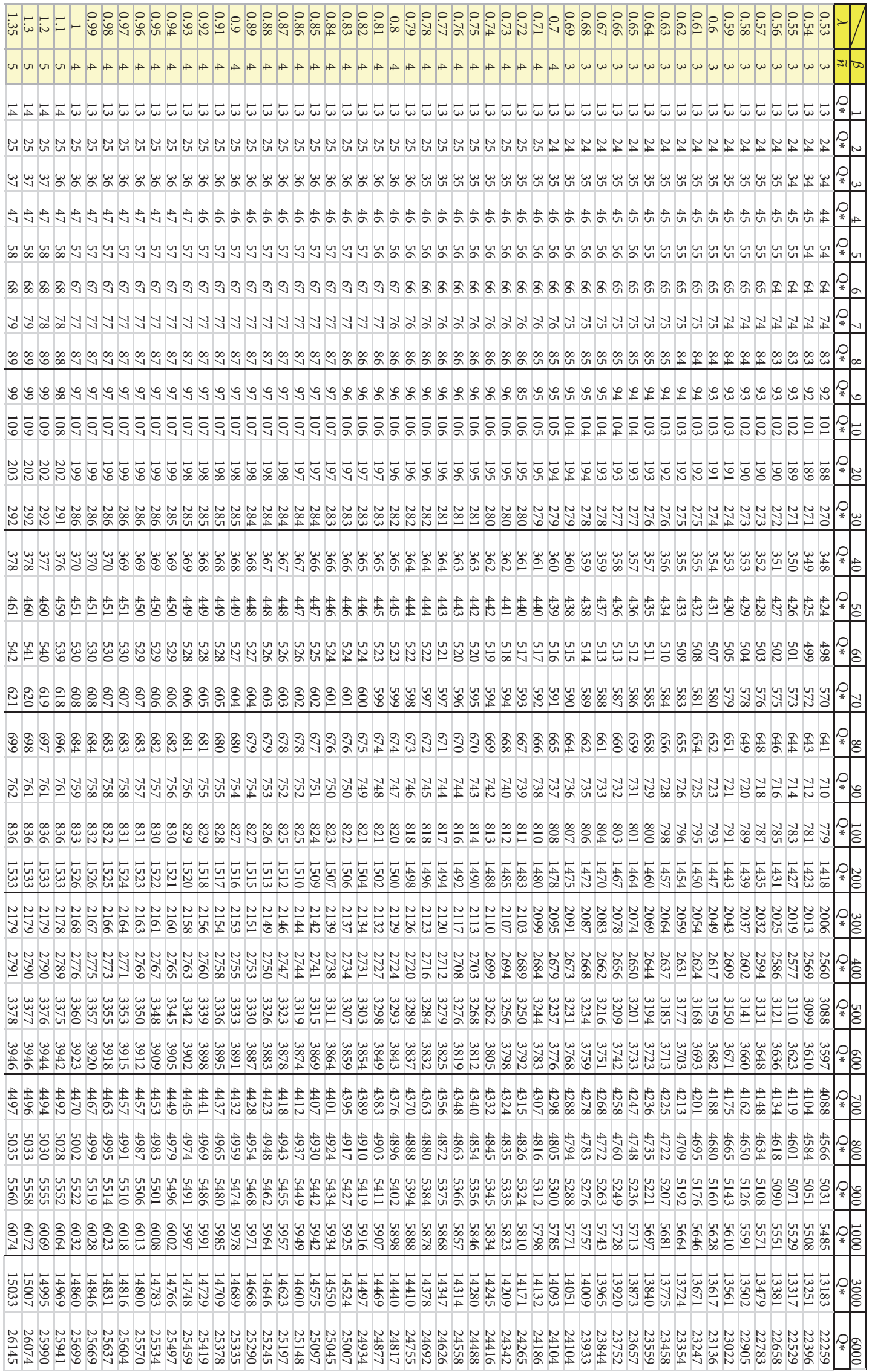

FIGURE 9: $Q^{*}$ under varied $\lambda, \beta$ when $k=2$. 


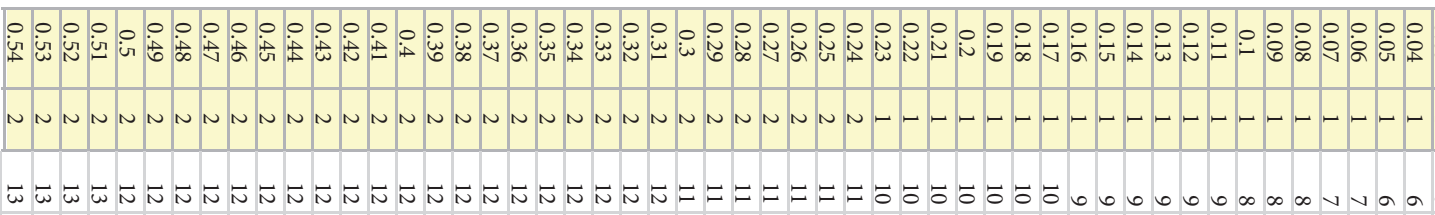

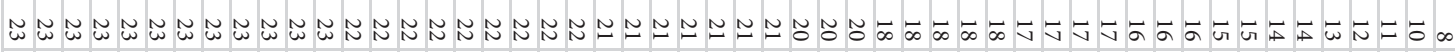

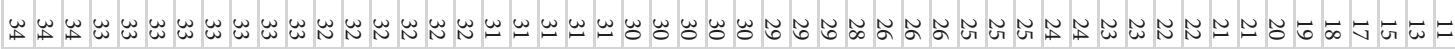

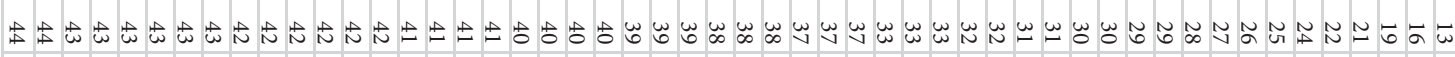
W

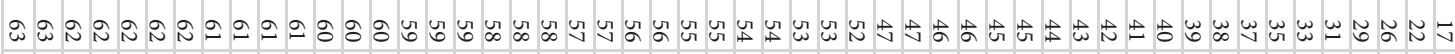

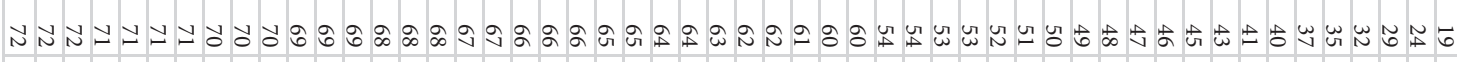

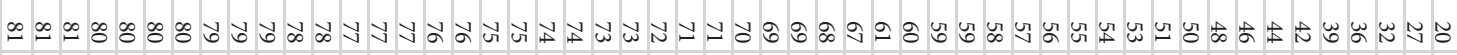
ஓ \& \& : : :

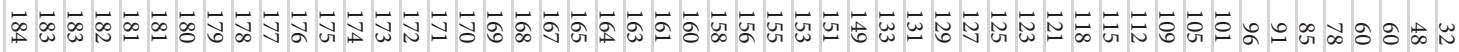

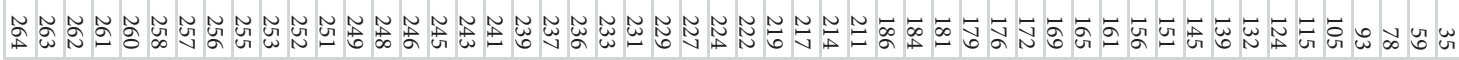

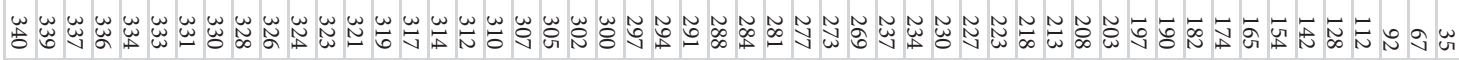

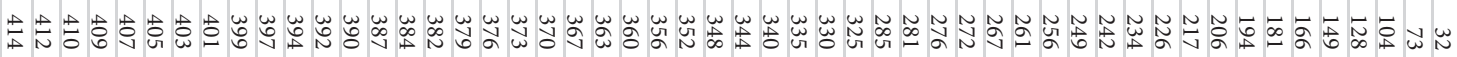

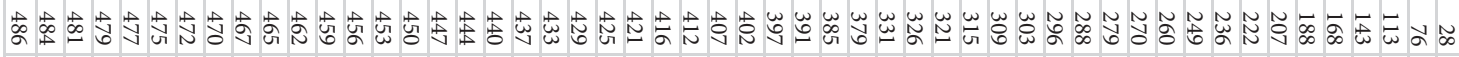

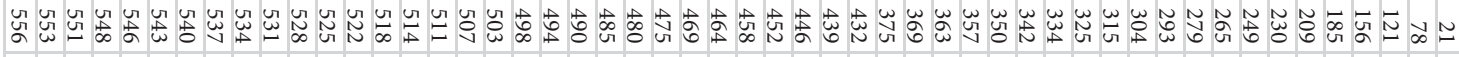

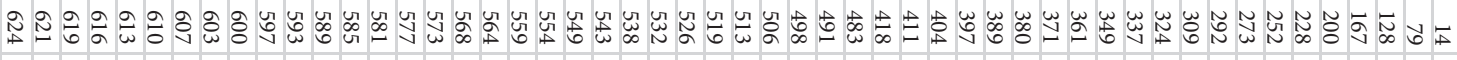

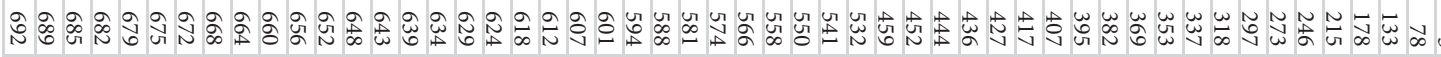

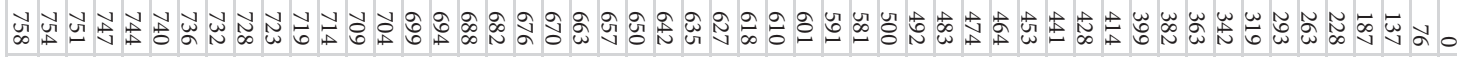

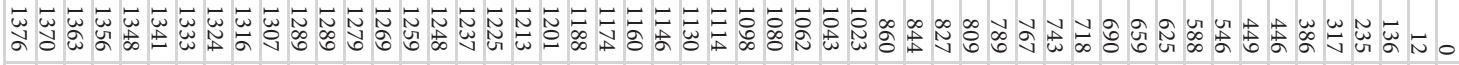

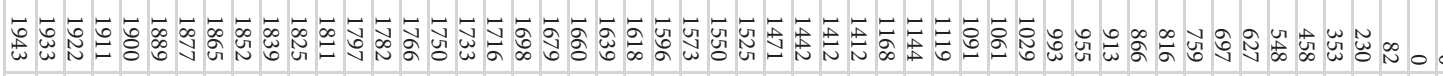

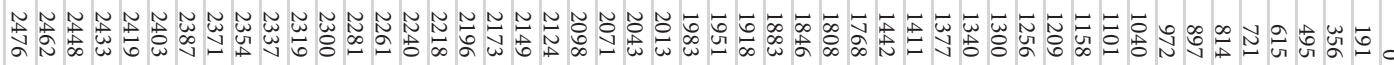

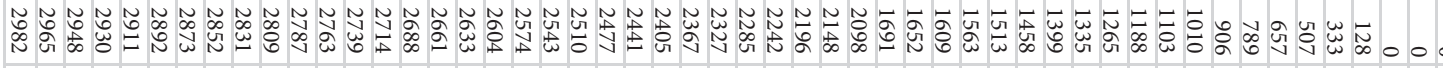

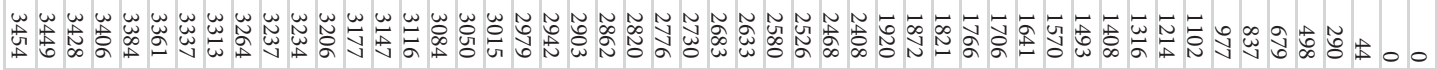

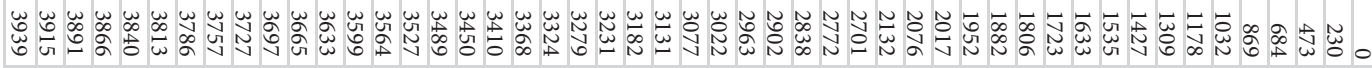

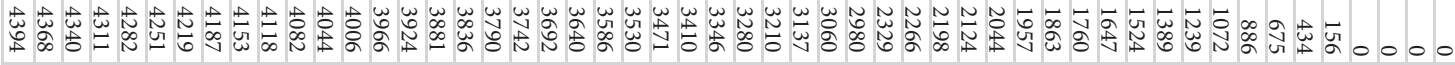

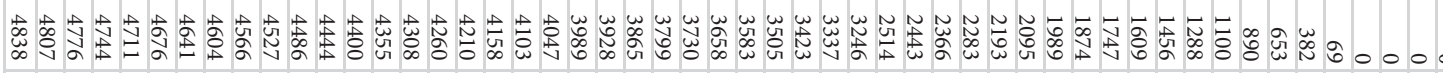

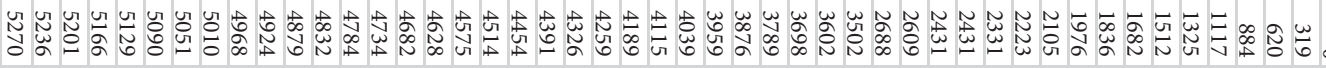

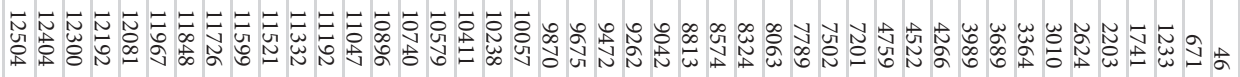

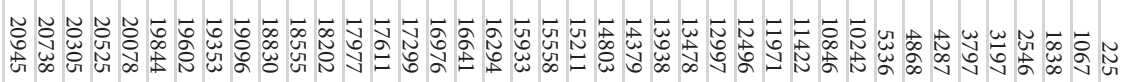

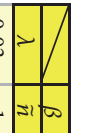




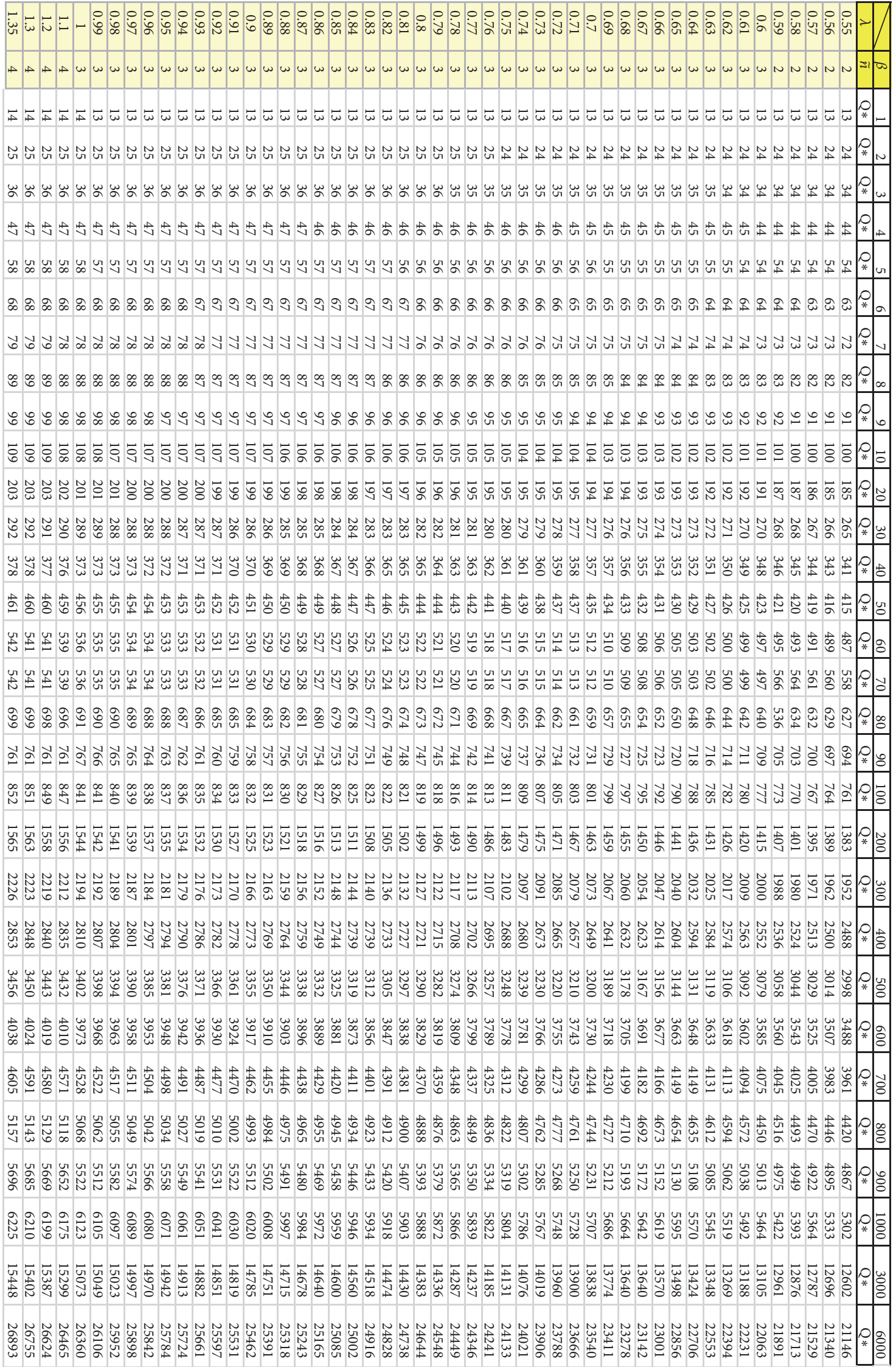

Figure 10: $Q^{*}$ under varied $\lambda, \beta$ when $k=3$. 

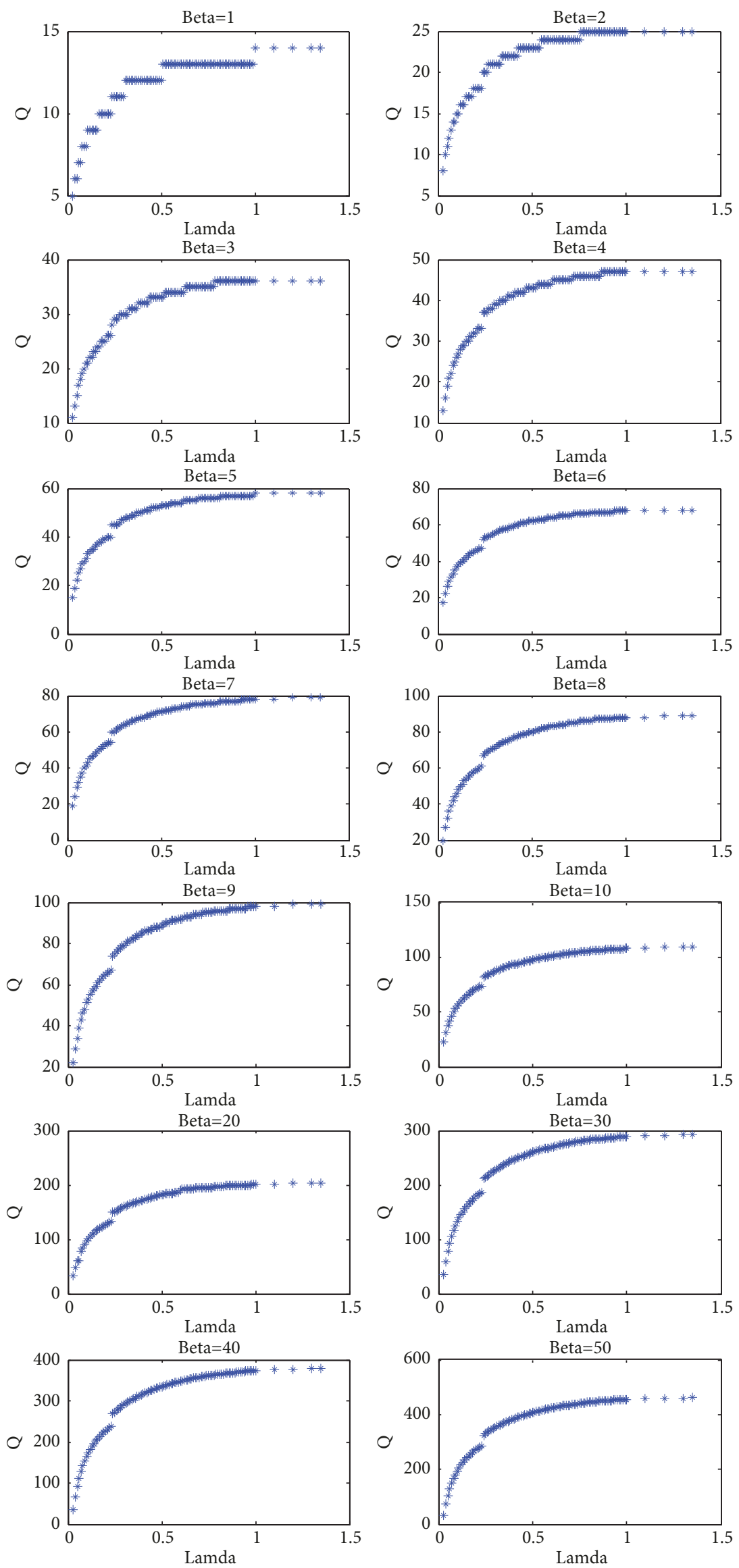

Figure 11: Continued. 

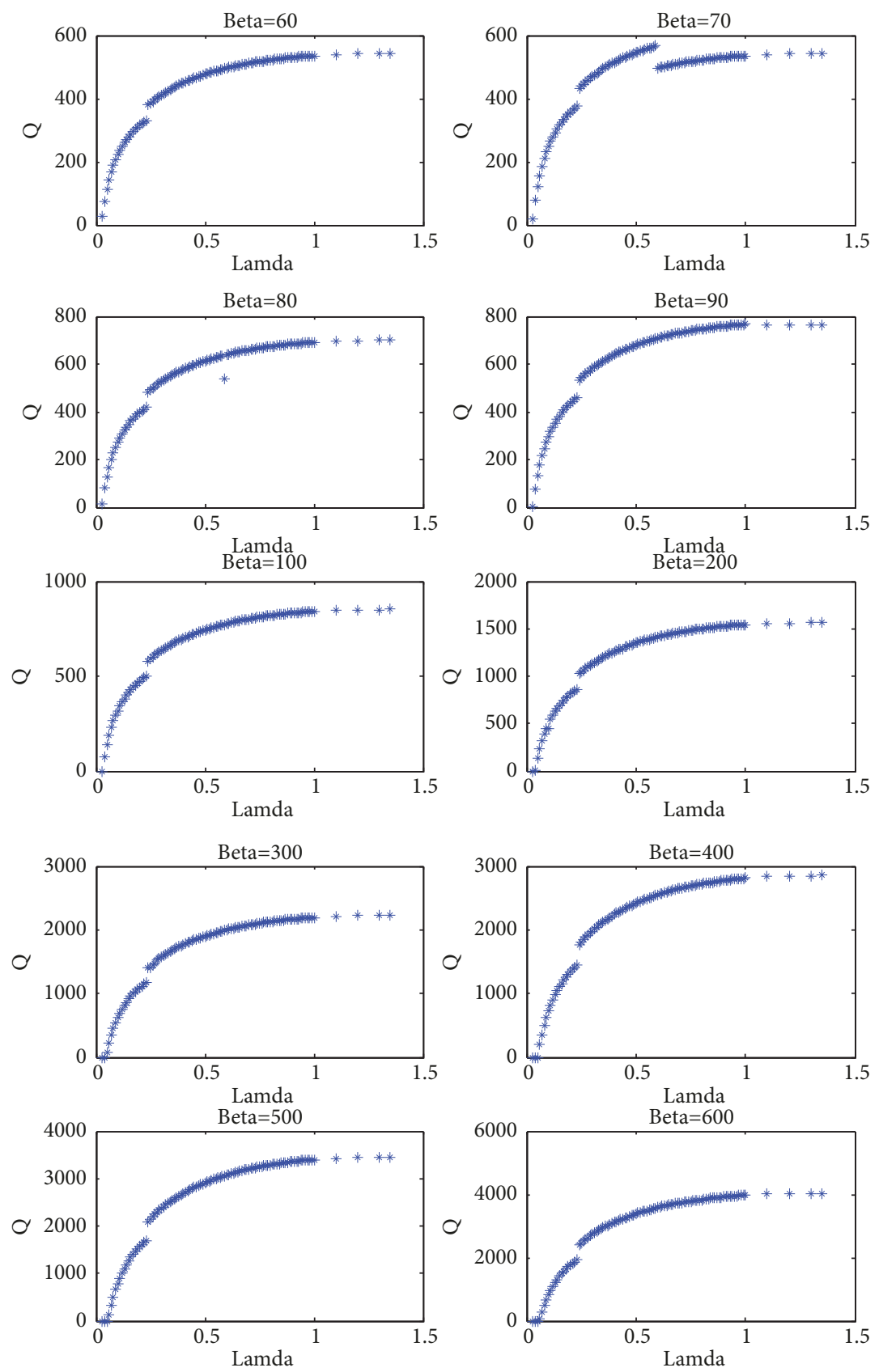

Figure 11: The relationships between $\lambda$ and $Q^{*}$ with respect to varied $\beta$ when $k=3$.

material inventory. However, its memoryless property is unrealistic. The Erlang is an IFR distribution, which better fits the nature of intermittent demand. Therefore, this paper proposes an algorithm to determine the optimal order quantity in a single echelon single electric power material inventory system for $(T, Q)$ policy. An empirical investigation was conducted to collaborate the validity of this new method by means of comparison with the classic Newsvendor model. The findings indicate that this new method outperforms the classic one in achieving cost reduction, which makes it more economic and practical. In addition, considering the complexity of this new method, an approximation and a heuristic algorithm is proposed. To sum up, the paper develops three algorithms for the optimal order quantity, each of which has their own advantages and disadvantages.

(1) The basic algorithm: this method has great advantages with regard to accuracy. However, it is time-consuming, computation-intensive, and not suitable for bulk operation.

(2) The approximation algorithm: it simplifies computational complexity by reducing iterative numbers within an acceptable error range. Such a method enables companies to enhance their efficiency of stock management with guaranteed accuracy, which is of great validity and utility in a realworld context. 
TABLE 4: Estimations of parameters $c$ and $a$ with respect to varied $\beta$.

\begin{tabular}{|c|c|c|c|c|c|c|c|}
\hline \multicolumn{4}{|c|}{$k=2$} & \multicolumn{4}{|c|}{$k=3$} \\
\hline$\beta$ & $c$ & $a$ & MAPE & $\beta$ & $c$ & $a$ & MAPE \\
\hline 1 & 12.48 & 3.68 & $14.29 \%$ & 1 & 12.08 & 3.08 & $14.29 \%$ \\
\hline 2 & 22.96 & 3.45 & $8.00 \%$ & 2 & 22.13 & 3.01 & $12.00 \%$ \\
\hline 3 & 32.85 & 3.42 & $10.81 \%$ & 3 & 31.58 & 3.01 & $11.11 \%$ \\
\hline 4 & 42.32 & 3.45 & $10.64 \%$ & 4 & 40.71 & 3.00 & $12.77 \%$ \\
\hline 5 & 51.68 & 3.44 & $10.34 \%$ & 5 & 49.58 & 3.00 & $13.79 \%$ \\
\hline 6 & 60.71 & 3.44 & $10.29 \%$ & 6 & 58.25 & 2.98 & $14.71 \%$ \\
\hline 7 & 69.63 & 3.43 & $11.39 \%$ & 7 & 66.81 & 3.00 & $15.19 \%$ \\
\hline 8 & 78.46 & 3.44 & $12.36 \%$ & 8 & 75.15 & 2.99 & $15.73 \%$ \\
\hline 9 & 87.03 & 3.41 & $12.12 \%$ & 9 & 83.35 & 2.98 & $16.16 \%$ \\
\hline 10 & 95.84 & 3.40 & $11.93 \%$ & 10 & 91.46 & 3.00 & $16.51 \%$ \\
\hline 20 & 176.43 & 3.43 & $13.30 \%$ & 20 & 174.26 & 3.00 & $16.91 \%$ \\
\hline 30 & 252.31 & 3.43 & $13.70 \%$ & 30 & 245.37 & 2.97 & $17.40 \%$ \\
\hline 50 & 394.41 & 3.43 & $14.53 \%$ & 50 & 382.59 & 3.02 & $17.88 \%$ \\
\hline 100 & 643.37 & 3.40 & $14.84 \%$ & 100 & 533.04 & 2.99 & $18.37 \%$ \\
\hline 500 & 3021.17 & 3.43 & $15.12 \%$ & 500 & 2982.11 & 3.04 & $19.86 \%$ \\
\hline 1000 & 4873.52 & 3.44 & $17.21 \%$ & 1000 & 4638.47 & 3.01 & $21.35 \%$ \\
\hline
\end{tabular}

(3) The heuristic algorithm: it derives the optimal order quantity by establishing a functional relation where the independent variable is $\lambda$ and the dependent variable is $Q^{*}$. This method is the simplest but has the least degree of accuracy among all algorithms.

In addition, these algorithms can also be applied to other electric power materials with intermittent demand within other industries.

\section{Appendix}

\section{A. Results of $\tilde{n}$ under Varied $\lambda, \beta, k$}

See Figures 7 and 8.

\section{B. Results of $Q^{*}$ under Varied $\lambda, \beta, k$}

See Figures 9 and 10.

\section{The Relationships between $\lambda$ and $Q^{*}$ with respect to Varied $\beta$ When $k=3$}

See Figure 11.

\section{Data Availability}

The data used to support the findings of this study were supplied by Shanghai Electric Power Company under license and so cannot be made freely available. Requests for access to these data should be made to Aiping Jiang, Chengzhong Rd., JiaDing Dist., Shanghai, China.

\section{Conflicts of Interest}

The authors declare that there are no conflicts of interest regarding the publication of this paper.

\section{Acknowledgments}

The research described in this paper has been funded by the National Science Foundation of China (Grant no. 71302053).

\section{References}

[1] R. M. Adelson, “The compound Poisson distribution," Journal of the Operational Research Society, vol. 17, no. 1, pp. 73-75, 1966.

[2] J. K. Friend, "Stock control with random opportunities for replenishment," Journal of the Operational Research Society, vol. 11, no. 3, pp. 130-136, 1960.

[3] F. Hanssmann, Operations Research in Production and Inventory Control, John Wiley and Sons, New York, NY, USA, 1962.

[4] J. Xiao, F. L. Lu, and X. Xiao, "Stohastic newsboy inventory control model and its solving on multivariate productd order and pricing," in Proceedings of the International Conference on Information Computing and Applications, pp. 65-72, 2010.

[5] S. Kébé, N. Sbihi, and B. Penz, "A Lagrangean heuristic for a two-echelon storage capacitated lot-sizing problem," Journal of Intelligent Manufacturing, vol. 23, no. 6, pp. 2477-2483, 2012.

[6] P. S. S. Uduman, A. Sulaiman, and R. Sathiyamoorthy, "News boy inventory model with demand satisfying SCBZ property," Bulletin of Pure and Applied Science, vol. 26, no. 1, pp. 145-150, 2007.

[7] D. Fathima, P. S. Sheik Uduman, and S. Srinivasan, "Generalization of newsboy problem with demand distribution satisfying the SCBZ property," International Journal of Contemporary Mathematical Sciences, vol. 6, no. 37-40, pp. 1989-2000, 2011.

[8] D. Fathima and P. S. S. Uduman, "Single period inventory model with stochastic demand and partial backlogging," International Journal of Management, vol. 24, no. 1, pp. 37-59, 2013.

[9] J. Kamburowski, "The distribution-free newsboy problem under the worst-case and best-case scenarios," European Journal of Operational Research, vol. 237, no. 1, pp. 106-112, 2014.

[10] Y.-K. Chen, C.-T. Chen, F.-R. Chiu, and J.-W. Lian, "Applying the bootstrap method to newsvendor model incorporating 
group buying for optimal price discount and order quantity," Kybernetes, vol. 46, no. 10, pp. 1692-1705, 2017.

[11] F. Hnaien, A. Dolgui, and D. D. Wu, "Single-period inventory model for one-level assembly system with stochastic lead times and demand," International Journal of Production Research, vol. 54, no. 1, pp. 186-203, 2016.

[12] S. Priyan and R. Uthayakumar, "Two-echelon multi-product multi-constraint product returns inventory model with permissible delay in payments and variable lead time," Journal of Manufacturing Systems, vol. 36, article no. 304, pp. 244-262, 2015.

[13] M. Keramatpour, S. T. A. Niaki, and S. H. R. Pasandideh, "A biobjective two-level newsvendor problem with discount policies and budget constraint," Computers \& Industrial Engineering, vol. 120, pp. 192-205, 2017.

[14] S. Axsäter, Inventory Control, Springer, 2015.

[15] P. Matheus and L. Gelders, "The (R, Q) inventory policy subject to a compound Poisson demand pattern," International Journal of Production Economics, vol. 68, no. 3, pp. 307-317, 2000.

[16] M. Z. Babai, Z. Jemai, and Y. Dallery, "Analysis of order-upto-level inventory systems with compound Poisson demand," European Journal of Operational Research, vol. 210, no. 3, pp. 552-558, 2011.

[17] W. T. Dunsmuir and R. D. Snyder, "Control of inventories with intermittent demand," European Journal of Operational Research, vol. 40, no. 1, pp. 16-21, 1989.

[18] F. Janssen, R. Heuts, and T. De Kok, "On the (R, s, Q) inventory model when demand is modelled as a compound Bernoulli process," European Journal of Operational Research, vol. 104, no. 3, pp. 423-436, 1998.

[19] R. H. Teunter, A. A. Syntetos, and M. Z. Babai, "Determining order-up-to levels under periodic review for compound binomial (intermittent) demand," European Journal of Operational Research, vol. 203, no. 3, pp. 619-624, 2010.

[20] A. K. Gupta, W.-B. Zeng, and Y. Wu, Probability and Statistical Models. Foundations for Problems in Reliability and Financial Mathematics, Springer Science and Business Media, 2010.

[21] M. A. Smith and R. Dekker, "On the (S-1, S) stock model for renewal demand processes: Poisson's poison," Probability in the Engineering and Informational Sciences, vol. 11, no. 3, pp. 375386, 1997.

[22] C. Larsen and G. P. Kiesmullerr, "Developing a closed-form cost expression for an $(\mathrm{R}, \mathrm{s}, \mathrm{nQ})$ policy where the demand process is compound generalized Erlang," Operations Research Letters, vol. 35, no. 5, pp. 567-572, 2007.

[23] C. Larsen and A. Thorstenson, "A comparison between the order and the volume fill rate for a base-stock inventory control system under a compound renewal demand process," Journal of the Operational Research Society, vol. 59, no. 6, pp. 798-804, 2008.

[24] C. Larsen and A. Thorstenson, "The order and volume fill rates in inventory control systems," International Journal of Production Economics, vol. 147, pp. 13-19, 2014.

[25] S. Saidane, M. Z. Babai, M. S. Aguir, and O. Korbaa, "Spare parts inventory systems under an increasing failure rate demand interval distribution," in Proceedings of the 41st International Conference on Computers and Industrial Engineering 2011, pp. 214-219, USA, October 2011.

[26] S. Saidane, M. Z. Babai, M. S. Aguir, and O. Korbaa, "On the performance of the base-stock inventory system under a compound Erlang demand distribution," Computers \& Industrial Engineering, vol. 66, no. 3, pp. 548-554, 2013.
[27] A. A. Syntetos, M. Z. Babai, and S. Luo, "Forecasting of compound erlang demand," Journal of the Operational Research Society, vol. 66, no. 12, pp. 2061-2074, 2015.

[28] R. Y. K. Fung, X. Ma, and H. C. W. Lau, “(T, S) policy for coordinated inventory replenishment systems under compound Poisson demands," Production Planning and Control, vol. 12, no. 6, pp. 575-583, 2001.

[29] Y. Zhao, "Analysis and evaluation of an assemble-to-order system with batch ordering policy and compound Poisson demand," European Journal of Operational Research, vol. 198, no. 3, pp. 800-809, 2009.

[30] E. Topan and Z. P. Bayindir, "Multi-item two-echelon spare parts inventory control problem with batch ordering in the central warehouse under compound Poisson demand," Journal of the Operational Research Society, vol. 63, no. 8, pp. 1143-1152, 2012.

[31] A. H. C. Eaves and B. G. Kingsman, "Forecasting for the ordering and stock-holding of spare parts," Journal of the Operational Research Society, vol. 55, no. 4, pp. 431-437, 2004.

[32] E. A. Trabka and E. W. Marchand, "The mean and variance of intervals between renewals of a type I counter with a censored Poisson input," Biological Cybernetics, vol. 7, no. 6, pp. 224-227, 1970. 


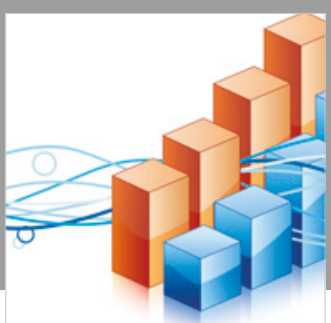

Advances in

Operations Research

\section{-n-m}
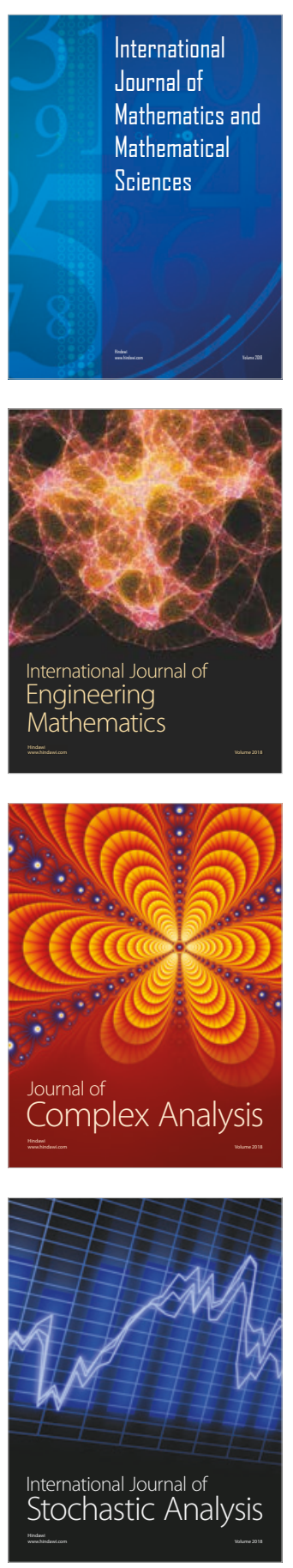
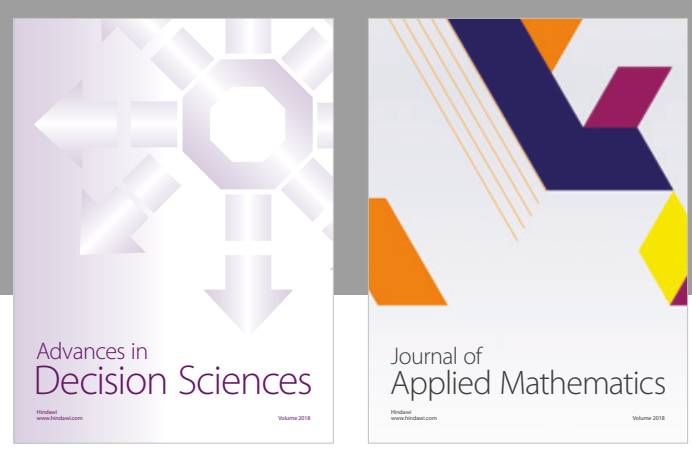

Journal of

Applied Mathematics
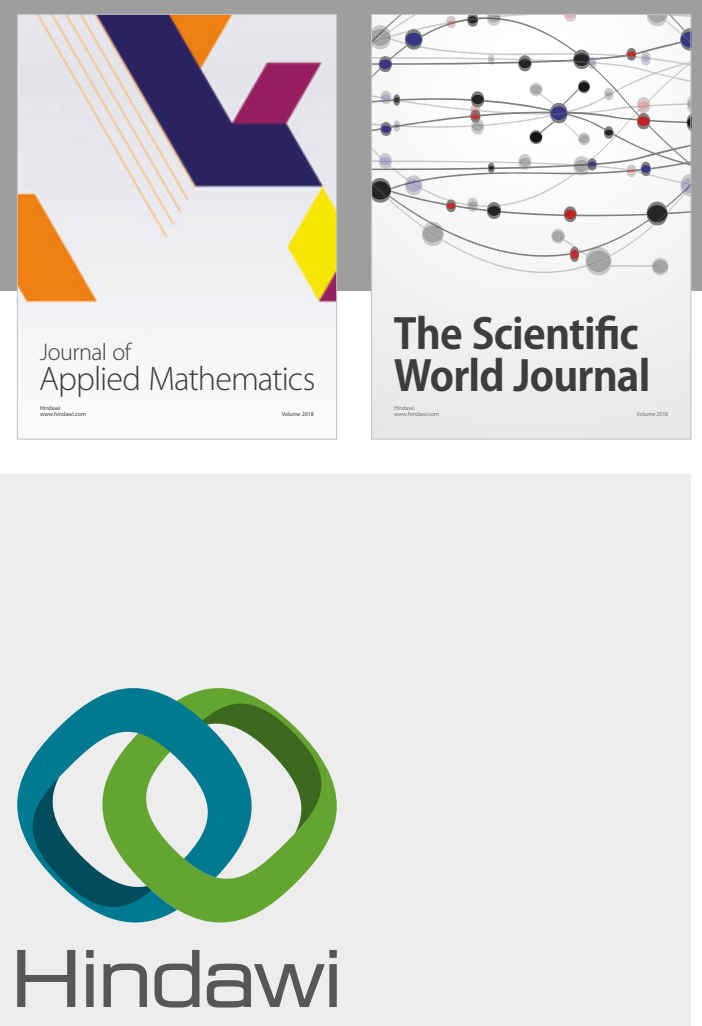

Submit your manuscripts at

www.hindawi.com

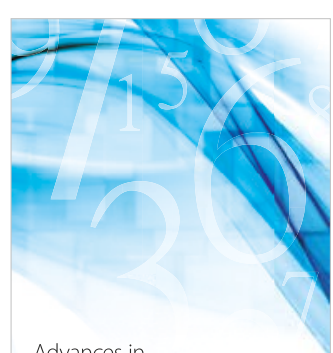

Advances in
Numerical Analysis
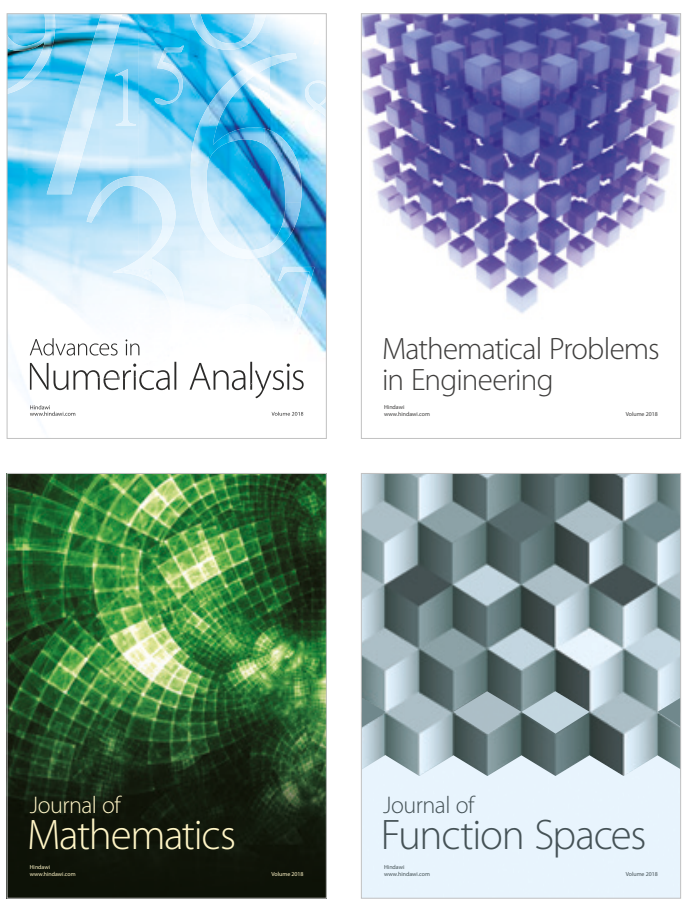

Mathematical Problems in Engineering

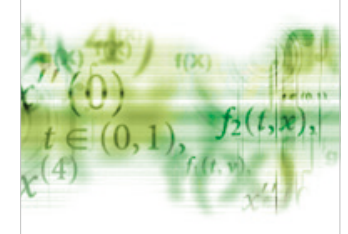

International Journal of

Differential Equations

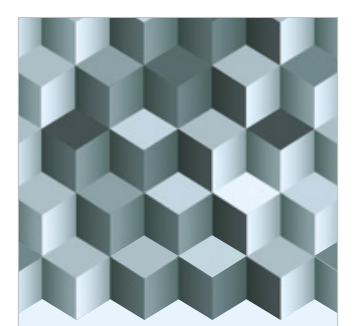

Journal of

Function Spaces

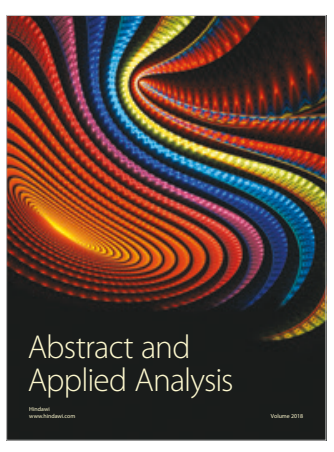

The Scientific

World Journal

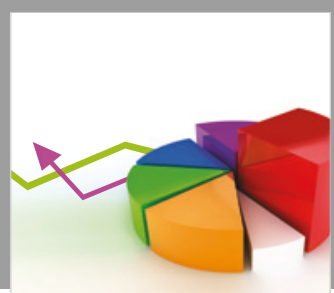

Journal of

Probability and Statistics
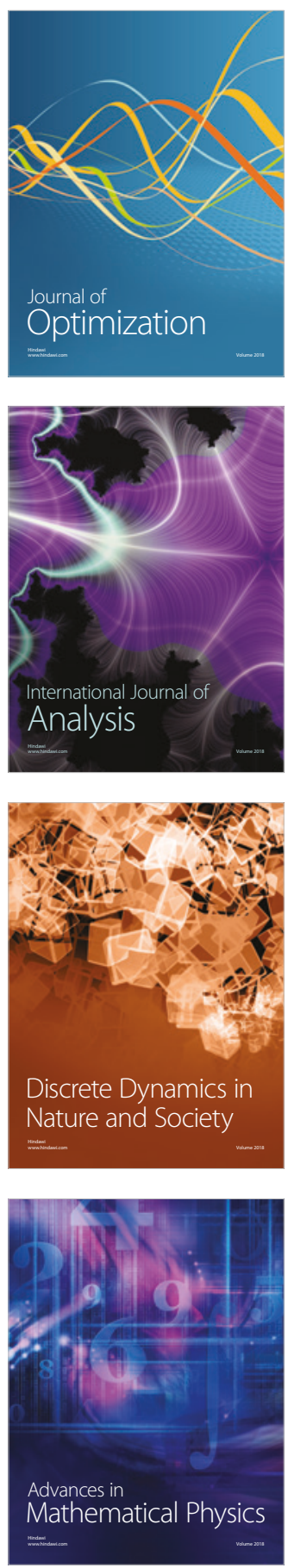